\title{
Supramolecular nesting of cyclic polymers
}

\author{
Dmitry V. Kondratuk, ${ }^{1}$ Luís M. A. Perdigão, ${ }^{2}$ Ayad M. S. Esmail, ${ }^{2}$ James N. O'Shea, ${ }^{2}$ \\ Peter H. Beton ${ }^{2}$ and Harry L. Anderson ${ }^{1 *}$
}

Monodisperse cyclic porphyrin polymers, with diameters of up to $21 \mathrm{~nm}$ (750 C-C bonds), have been prepared using Vernier template-directed synthesis. The ratio of the intrinsic viscosities for cyclic and linear topologies is $\mathbf{0 . 7 2 ,}$ indicating that these polymers behave as almost ideal flexible chains in solution. When deposited on gold surfaces, the cyclic polymers display a new mode of two-dimensional supramolecular organisation, combining encapsulation and nesting: one nanoring adopts a near-circular conformation thus allowing a second nanoring to be captured within its perimeter, in a tightly folded conformation. Scanning tunnelling microscopy reveals that nesting occurs in combination with stacking when nanorings are deposited under vacuum, whereas when they are deposited directly from solution under ambient conditions, there is stacking or nesting, but not a combination of both.

The tertiary structures of biological macromolecules are achieved through folding, coiling and multiplex formation, driven by the cooperative effect of many weak interactions ${ }^{1}$. Synthetic monodisperse macromolecules with similar cooperative folding behaviour provide a viable approach to the programmed fabrication of $3 \mathrm{D}$ nanostructures ${ }^{2-5}$. Here we show that cyclic porphyrin polymers, with molecular weights of 30-60 kDa, self-assemble into nested structures on a gold surface. These nested assemblies are only observed when the cyclic polymer has 30 or more repeat units, in keeping with the predictions of a simple geometrical model.

The importance of non-covalent self-assembly in biology has inspired many studies of supramolecular organisation on surfaces ${ }^{6-8}$, generating 2D assemblies with progressively escalating complexity, from early work on simple structures such as clusters ${ }^{9}$ and rows ${ }^{10,11}$, to nanoporous arrays ${ }^{12,13}$, host-guest architectures $^{14-16}$, hierarchical arrangements ${ }^{17}$, and multicomponent assemblies ${ }^{17-19}$. However, cooperative conformational control has proved difficult to achieve, and this remains a significant gulf between artificial and biological systems. One reason for this difference is that biological macromolecules are much more flexible than the component molecules studied in 2D supramolecular assemblies which are small and, with some exceptions $^{20,21}$, are often treated as quasi-rigid building blocks. Here we illustrate how interactions between large flexible molecules can result in biomimetic cooperative conformational organisation.

Studies of linear and cyclic butadiyne-linked zinc porphyrin oligomers (structures $\boldsymbol{l}-\mathbf{P} \boldsymbol{N}_{\mathrm{THS}}$ and $\boldsymbol{c}-\mathbf{P} \boldsymbol{N}$, Fig. 1) have shown that the distance between the centres of the porphyrin units along the chain is $a=1.35 \mathrm{~nm}^{5,22,23}$. Thus the contour length of a linear oligomer, or the perimeter of a nanoring, is $N a$, where $N$ is the number of porphyrin repeat units. Previously we have shown that nanorings adsorbed on $\mathrm{Au}(111)$ exhibit flexibility ${ }^{24-26}$, and also that they can act as nanoscale traps for other adsorbed species, such as $\mathrm{C}_{60}$ guest molecules ${ }^{27}$. However, in order for one nanoring to be adsorbed inside another, the dimensions of the nanoring must exceed a critical threshold. The footprint area of a nanoring is simply $\mathrm{Nad}$, where $d$ is the effective width of the chains (ca. $2.1 \mathrm{~nm}$; see below). Note that this area is independent of conformation. The maximum area enclosed within the ring, and available for trapping a second nanoring, is $\pi(N a / 2 \pi-d / 2)^{2}$. In order for selftrapping to occur, equation (1) must be satisfied,

$$
\pi(N a / 2 \pi-d / 2)^{2}>N a d
$$

which implies that the nanoring needs to consist of more than 29 porphyrin units $(N \geq 29)$.

The largest ring that we have synthesised previously is $\boldsymbol{c}$-P24 $(N=24)^{5}$. Here we describe how Vernier template-directed synthesis can be extended to prepare rings of up to 50 porphyrin units, and we show, using scanning tunnelling microscopy (STM), that rings with $N \geq 30$ support a nested packing in which one nanoring is trapped in a compact conformation inside a second nanoring.

The synthesis of these very large macrocycles was achieved through a rational extension of Verniertemplating, by the cyclo-polymerisation of a linear porphyrin 10-mer $\boldsymbol{l}$-P10 in the presence of a 6-site template T6 (favouring formation of the cyclic 30-mer, c-P30) or an 8-site template T8 (favouring formation of the cyclic 40-mer, $\boldsymbol{c - P 4 0}$ ), as depicted in Fig. 1. In each case the expected Vernier product dominates the product distribution. These reactions are not completely selective, and cyclic polymers with 10, 20, 30, 40 and 50 porphyrin units can be isolated by recycling gel permeation chromatography (GPC). There has been much previous work on the synthesis of cyclic polymers $^{28-32}$, but to the best of our knowledge, nanorings $\boldsymbol{c}$-P30, $\boldsymbol{c}$-P40 and $\boldsymbol{c}$-P50 are the largest monodisperse covalent carbocyclic macrocycles yet reported. The 50-porphyrin nanoring $\boldsymbol{c}$-P50 contains an uninterrupted ring of $750 \mathrm{C}-\mathrm{C}$ bonds and has a diameter of $21 \mathrm{~nm}$. The largest previously reported synthetic macrocyle is a 32-porphyrin nanoring containing a cycle of 400 carbon atoms ${ }^{33}$.

\footnotetext{
${ }^{1}$ Department of Chemistry, University of Oxford, Oxford OX1 3TA, UK. ${ }^{2}$ School of Physics \& Astronomy, University of Nottingham, Nottingham, NG7 2RD, UK. *e-mail: harry.anderson@chem.ox.ac.uk, peter.beton@nottingham.ac.uk
} 
a)

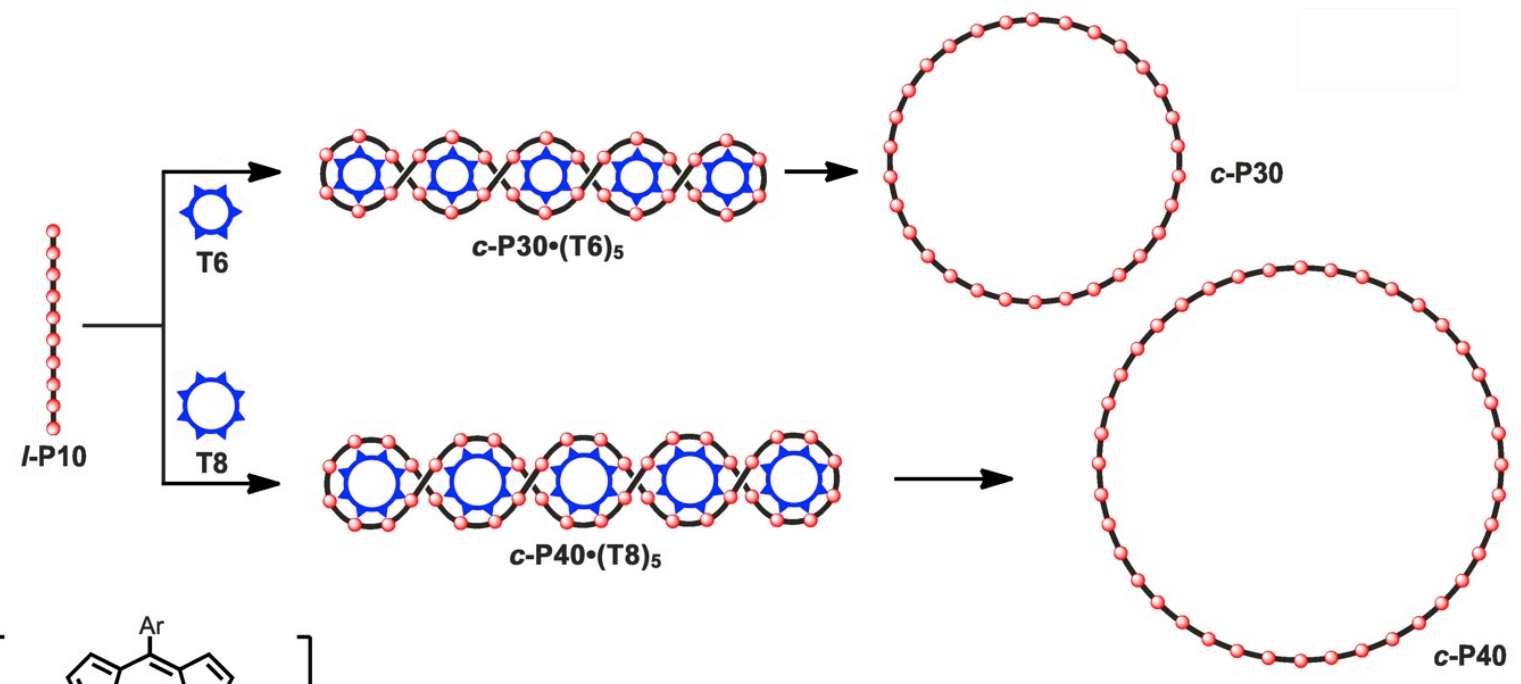

b)
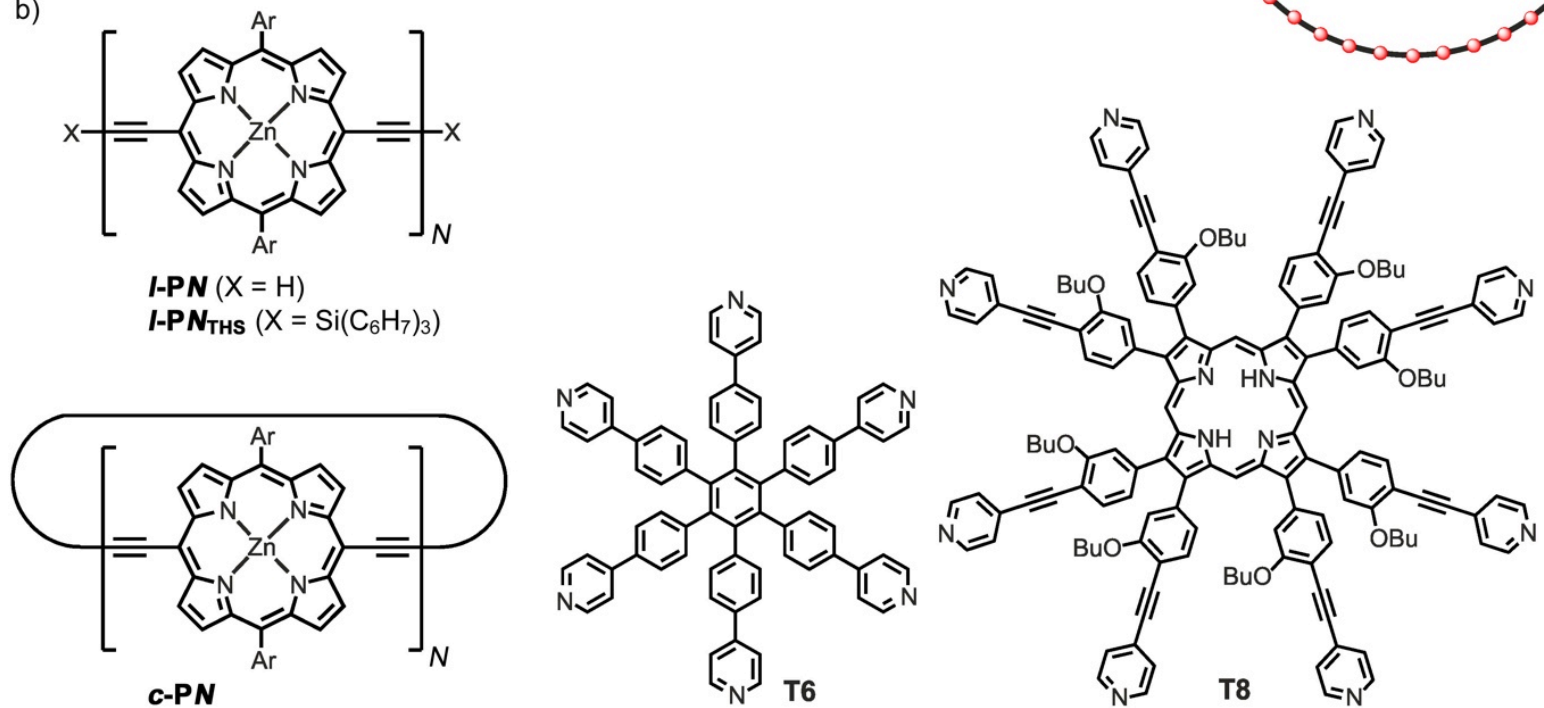

Figure 1. (a) Templated synthesis of the nanorings c-P30 and c-P40. Reagents: i) $\mathrm{PdCl}_{2}\left(\mathrm{PPh}_{3}\right)_{2}$, Cul, benzoquinone, $i-\mathrm{Pr}_{2} \mathrm{NH}$; ii) pyridine; (b) Structures of I-PN, I-PN $N_{\text {THS }}$ c-PN, T6 and T8; $\mathrm{Ar}=3,5$-bis(octyloxy)phenyl.

\section{Results and discussion}

Synthesis. We investigated the palladium-catalysed oxidative coupling of the linear zinc-porphyrin 10-mer $\boldsymbol{l}$-P10 in the presence of hexa-pyridyl template $\mathbf{T 6}^{23,34}$ and octa-pyridyl template $\mathbf{T 8}^{35}$ (Fig. 1). These reactions are expected to generate the nanoring-template complexes

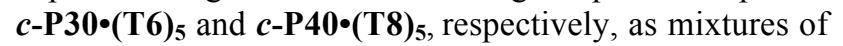
stereoisomers; the templates were displaced from the nanorings by addition of pyridine, prior to analysis and purification. Crude reaction mixtures were analysed by GPC and compared with the distribution of products from coupling under identical conditions in the absence of a template (Fig. 2). When no template is present, all the products are linear polymers; traces of linear oligomers $\boldsymbol{l}$ P10, $\boldsymbol{l}$-P20 and $\boldsymbol{l}$-P30 can be detected but there is no evidence of cyclic products (Fig. 2a).

Coupling of $\boldsymbol{l}$-P10 in the presence of T6 gives the expected cyclic porphyrin 30-mer $\boldsymbol{c}$-P30 as the main product (34\% analytical yield, $26 \%$ isolated yield), however other by-products such as $\boldsymbol{c}$-P10, $\boldsymbol{c}$-P20, $\boldsymbol{c}$-P40 and $\boldsymbol{c}$-P50 are also formed (Fig. 2b). The reaction was tested using a range of $\boldsymbol{l}$-P10 / T6 ratios and the yield of c-P30 was found to be highest (34\% analytical yield) for a l-P10 / T6 ratio of 3/5. Reducing the amount of template below this stoichiometry increases the ratio of $\boldsymbol{c}-\mathbf{P 3 0} / \boldsymbol{c}$-P10, but reduces the yield of $\boldsymbol{c}$-P30 due to increased formation of linear polymers. Increasing the amount of template above $5 / 3$ equivalents reduces the ratio $\boldsymbol{c}$-P30 / $\boldsymbol{c}$-P10 and reduces the yield of $\boldsymbol{c}-\mathbf{P 3 0}$.

Changing the template to $\mathbf{T 8}$ shifts the productdistribution to make $\boldsymbol{c}$-P40 predominate $(36 \%$ analytical yield, $27 \%$ isolated yield), as expected from the Vernier principle (Fig. 2c). The yield of $\mathbf{c - P 4 0}$ was found to be greatest for a $\boldsymbol{l}$-P10/T8 ratio of $1: 1 \quad(36 \%$ analytical yield). Reducing the amount of template below this stoichiometry increases the ratio of $\boldsymbol{c}-\mathbf{P 4 0} / \boldsymbol{c}$-P10, but reduces the yield of $\boldsymbol{c}-\mathbf{P 4 0}$ due to increased formation of linear polymers. Increasing the amount of template above 1 equivalent, reduces the ratio $\boldsymbol{c}$-P40 / $\boldsymbol{c}$-P10 and reduces the yield of $\boldsymbol{c}-\mathbf{P} \mathbf{4 0}$.

The cyclic products, $\boldsymbol{c}-\mathbf{P 1 0}, \boldsymbol{c}-\mathbf{P 2 0}, \boldsymbol{c - P 3 0}, \boldsymbol{c}-\mathbf{P 4 0}$ and c-P50, were isolated by recycling GPC (see Supplementary Information). Their ring-sizes were established by MALDI-TOF mass spectrometry and STM imaging (as discussed below), while their purities were confirmed by analytical GPC and ${ }^{1} \mathrm{H}$ NMR spectroscopy. 


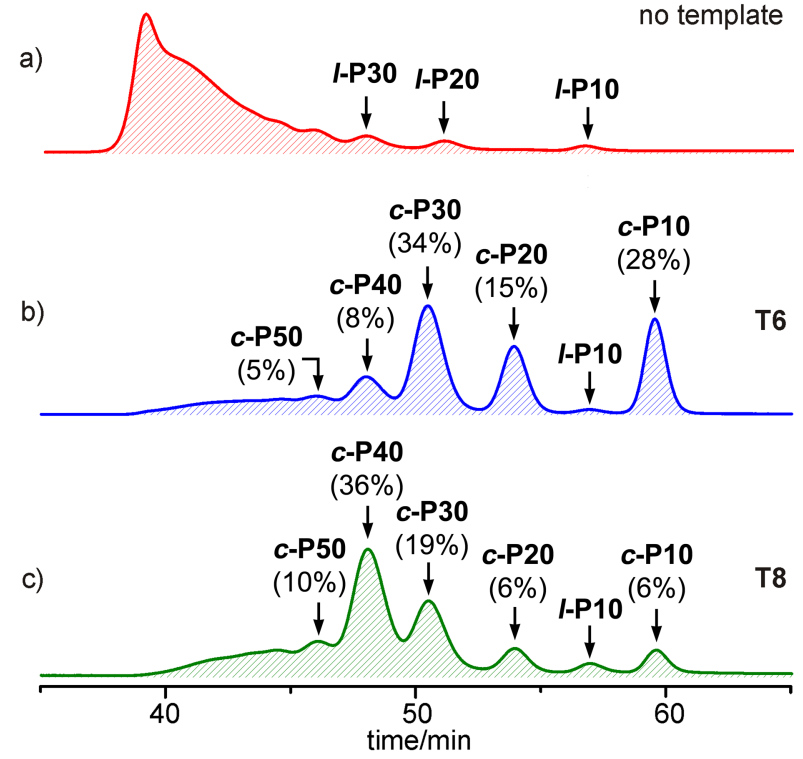

Figure 2. Analytical GPC traces (toluene/1\% pyridine, detection at $500 \mathrm{~nm}$ ) of the crude reaction mixtures from coupling I-P10 (a) in the absence of a template, (b) in the presence of T6, and (c) in the presence of T8. The catalysts and 1,4-benzoquinone were removed by passing the sample through a short GPC column in $\mathrm{CHCl}_{3} / 10 \%$ pyridine as eluent. The analytical yields were determined by comparison of resolved peaks in the corresponding recycling GPC traces (see Supplementary Information).

Gel Permeation Chromatography. All the isolated nanorings gave sharp single-component GPC profiles. The elution times confirm the molecular weights, when calibrated with data from previously characterised nanorings $(c-P 6, c-P 8, c-P 12, c-P 16, c-P 18$ and $c$-P24), as shown from the plot of $\log$ molecular weight, $\log M, v s$. elution time $t$ in Fig. 3. The points for linear and cyclic oligomers define two parallel straight lines, reflecting the more compact conformations of the cyclic oligomers. For molecular weights in the linear range for a GPC column, the elution time $t$ is related to the molecular hydrodynamic volume $V_{\mathrm{h}}$ by equation $2^{36}$,

$$
\log V_{\mathrm{h}}=a-b t
$$

where $a$ and $b$ are constants characteristic to the column. The hydrodynamic volume is related to the molecular weight $M$ and the intrinsic viscosity $[\eta]$ by equation 3 (where $K$ is a constant) ${ }^{37}$.

$$
V_{\mathrm{h}}=K M[\eta]
$$

Combining equations 2 and 3 gives:

$$
\log M=a^{\prime}-b t
$$

where $a^{\prime}=(a-\log K-\log [\eta])$. In Fig. 3, the data for cyclic and linear oligomers are fitted to two parallel straight lines, according to equation 4 , giving $a_{\text {cyclic }}^{\prime}=$ $7.213 \pm 0.003, a_{\text {linear }}^{\prime}=7.073 \pm 0.003$ and $b=0.053 \pm$ $0.001 \mathrm{~min}^{-1}$. If we assume that $K$ is independent of the linear or cyclic topology of the polymer, then the ratio of intrinsic viscosities for cyclic and linear chains of the same molecular weight is given by equation 5 ,

$$
\Delta a^{\prime}=a_{\text {linear }}^{\prime}-a_{\text {cyclic }}^{\prime}=\log \left([\eta]_{\text {cyclic }} /[\eta]_{\text {linear }}\right)
$$

which gives $[\eta]_{\text {cyclic }} /[\eta]_{\text {linear }}=0.72 \pm 0.01$. This ratio is close to the theoretical value of 0.66 for ideal flexible macromolecules in a theta solvent ${ }^{29,38}$, and to the values found experimentally for other linear and cyclic polymers $\left([\eta]_{\text {cyclic }} /[\eta]_{\text {linear }}=0.6-0.7\right)^{29,39,40}$, indicating that the porphyrin polymers behave as flexible chains in solution.

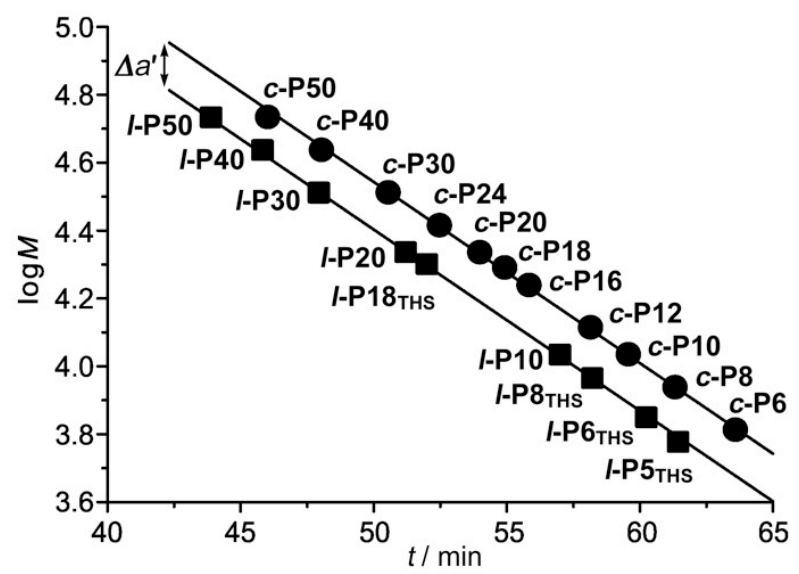

Figure 3. GPC retention times of cyclic (circles) and linear (squares) porphyrin oligomers plotted against log molecular weight (all recorded in toluene/1\% pyridine). Data are fitted to two parallel lines, according to equation 4.

Scanning Tunnelling Microscopy. The cyclic structures of $c-P 10, c-P 20, c-P 30, c-P 40$ and $c$-P50 were confirmed using STM. Molecules were transferred from solution onto a $\mathrm{Au}(111)$ surface held under ultrahigh vacuum using electrospray deposition ${ }^{5,24,25}$ and Fig. 4 shows STM images of each cyclic polymer. In common with our previous work ${ }^{5,25,26}$ the nanorings are preferentially adsorbed in configurations overlapping, or partially overlapping, terrace steps on the $\mathrm{Au}(111)$ surface, and the porphyrin macrocycles lie parallel to the substrate. In many images it is possible to resolve the porphyrin units providing confirmation of the degree of polymerisation, simply by counting the bright contrast features around the perimeter of a nanoring. This numbering is included for the $\boldsymbol{c}$-P30 and $\boldsymbol{c}$-P40 nanorings in Fig. 4 (further images, including those acquired for larger areas are included in the Supplementary Information (SI)).

We also observe stacking of $\boldsymbol{c}$-P30, $\boldsymbol{c}$-P40 and $\boldsymbol{c}$-P50 nanorings, with two or three nanorings lying directly above each other, in an eclipsed geometry, as reported recently for $\boldsymbol{c} \mathbf{- P 2 \mathbf { 4 } ^ { 2 6 }}$. These assemblies can be identified from their topographic height $(\sim 0.4 \mathrm{~nm}$ for double stacks, $\sim 0.7 \mathrm{~nm}$ for triple stacks) in contrast to the single-height rings (height $\sim 0.1 \mathrm{~nm}$ ) observed for $\boldsymbol{c}$-P20 and $\boldsymbol{c}$-P10 (see height profiles in SI). 

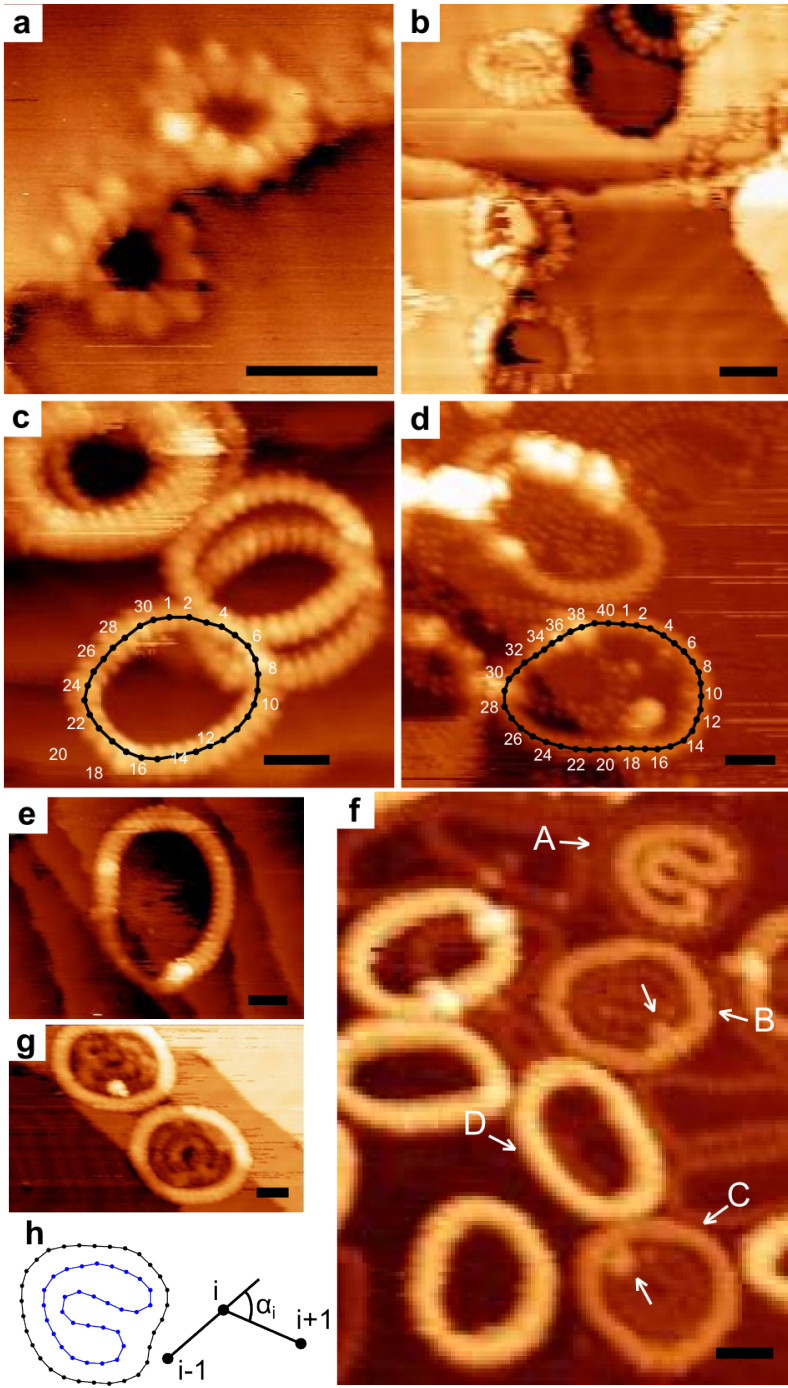

Figure 4. STM images of $c-P 10$ (a), c-P20 (b), c-P30 (c), c-P40 (d), c-P50 (e) on a gold surface. Black scale bar is $5 \mathrm{~nm}$ for each image. Selected rings in images (c) and (d) have numbering of the subunits included. Nested nanoring complexes of $\boldsymbol{c}$-P30 (f) and $\boldsymbol{c - P 4 0}(\mathrm{g})$. In (f) A is nested double within single structure, $B$ and $C$ are nested single within double structures; $D$ is a triple stack nanoring. The arrows identify bright features on the inner nanoring discussed in text. The schematic in (h) shows a representation of the nested structure $A$ and the definition of the angle, $\alpha_{i}$. All scale bars are $5 \mathrm{~nm}$; scanning parameters are included in $\mathrm{SI}$.

The nested self-trapped supramolecular arrangement is observed for nanorings with 30 and 40 porphyrin groups. In Fig. 4f, we show a zoomed image of $\boldsymbol{c}$-P30; in the top right corner a tightly packed nanoring with bright contrast is enclosed within a lower contrast near-circular nanoring (marked $A$ ). The contrast levels correspond to different topographic heights and we identify the higher contrast interior structure as a stack of two nanorings, while the outer near-circular conformation is a singleheight nanoring. There are two other nested structures in this image (marked $B$ and $C$ ) in which the overall conformation of the inner and outer nanorings are very similar to structure $A$, but the relative contrast of the inner and outer nanorings is reversed. Thus $B$ and $C$ are both formed from a single-height nanoring enclosed within a near-circular stack of two nanorings. Similarly, the nested
c-P40 structures shown in Fig. 4g, have single-height inner rings within double-height outer rings. In Fig. $4 \mathrm{f}$ there are also several non-nested structures with brighter contrast which we identify, from their topographic height as stacks of three nanorings (for example $D$ ).

Table 1 | Distribution of nanorings in identifiable nested, nonnested and open stacked structures from electrospray deposition under UHV. ${ }^{\text {a }}$

\begin{tabular}{|c|c|c|c|c|c|c|}
\hline & \multicolumn{3}{|c|}{$\begin{array}{c}\text { Nanorings in nested } \\
\text { structures }\end{array}$} & \multicolumn{3}{|c|}{$\begin{array}{c}\text { Nanorings in open non- } \\
\text { nested structures }\end{array}$} \\
\hline & 1-in-1 & 1-in-2 & 2-in-1 & single & 2-stack & 3-stack \\
\hline$c-\mathbf{P 3 0}$ & $1.0 \%$ & $9 \%$ & $1.5 \%$ & $7 \%$ & $16 \%$ & $65.5 \%$ \\
\hline$c$-P40 & $1.0 \%$ & $22.5 \%$ & $1.5 \%$ & $3 \%$ & $20 \%$ & $52 \%$ \\
\hline $\begin{array}{l}\text { a Statis } \\
\text { nanorir } \\
\text { disorde } \\
\text { denote } \\
\text { structu }\end{array}$ & based & nd are & includ & $\begin{array}{l}\text { here; } 1-i \\
\text { and do }\end{array}$ & s and 3 & $\begin{array}{l}0 \text { c-P30 } \\
\text { rlapping } \\
\text { ad } 2 \text {-in-1 } \\
\text { e nested }\end{array}$ \\
\hline
\end{tabular}

The fraction of $\boldsymbol{c}$-P30 and $\boldsymbol{c}$-P40 in various nested and non-nested geometries is analysed in Table 1, showing that the single-in-double is by far the most common nested structure.

The conformation of the compact nested nanoring is most clearly resolved for nanoring $A$ where a series of three 'hairpin' bends through $\sim 180^{\circ}$ deform the nanoring into a ' $\mathrm{C}$ ' shape. The separation between porphyrin groups on neighbouring polymers is $d=2.1 \pm 0.1 \mathrm{~nm}$ in regions where the curvature is small (for example the boundary between single-height nanorings slightly above the letter $C$ in Fig. 4f), close to the separation measured for linear oligomers (see SI); this value is used in our estimate of the minimum size for nesting in the introduction. However, the separation of porphyrin groups in the inner and outer nanorings forming the nested structure can deviate from this value. In particular, the separation measured for structure $A$ is in the range 1.6-1.8 $\mathrm{nm}$ in regions where the curvature of the inner nanoring is highest, i.e. close to the hairpin bends.

It is possible to map the porphyrin positions in the nested structure $A$, (see schematic in Fig. 4h), from which we estimate the elastic energy required to form the nested conformation. Approximating the shape to 30 segments with an angle $\alpha_{i}$ between the $i$ th and $(i+1)$ th segments (see Fig. 4h) we estimate,

$$
E_{B}=\frac{\kappa_{B}}{2 a} \sum_{i=1}^{N} \alpha_{i}^{2}
$$

where $\kappa_{\mathrm{B}}$ is the bending coefficient, estimated previously to be 0.07 and $0.03 \mathrm{nN} \mathrm{nm}^{2}$ for double and single layer nanorings respectively ${ }^{24}$. Accordingly we estimate $E_{\mathrm{B}} \approx$ $2.6 \mathrm{eV}$ for the nested double-height nanoring in Fig. $4 \mathrm{f}$. Note that this energy, though large, is distributed over 60 porphyrin-butadiyne groups.

In considering the overall energy difference between a nested double/single-stacked nanoring and triply stacked structure we note that there is a gain in adsorption energy arising from the interaction of an additional nanoring with the gold surface. This must be greater than the energy required to elastically deform a coiled nanoring in order for the nested structure to be stable. The typical adsorption energies of porphyrins on $\mathrm{Au}(111)$ are in the 
range 2-4 eV; for example the adsorption energy of tetraphenylporphyrin on $\mathrm{Au}(111)$ has been calculated ${ }^{41}$ to be $3.3 \mathrm{eV}$. Since the overall adsorption energy would scale with $N$, this would result in an adsorption energy of $\sim 100 \mathrm{eV}$ for $\boldsymbol{c}-\mathbf{P 3 0}$, much greater than the bending energy estimated above. For these large molecules which are composed of 4770 atoms high-level calculations of adsorption energies are not currently possible, but this order of magnitude argument illustrates that if there is a conformation available which can accommodate a nested structure, we would expect it to be energetically stable.

In previous work on $\boldsymbol{c}$-P24, we showed that the stacking is related to the choice of solvent ${ }^{26}$ (in particular it is suppressed through the addition of pyridine to the electrospray solution). To determine whether the nesting, and its combination with stacking, is also solvent dependent we have investigated layers formed by immersion under ambient conditions using a flameannealed $\mathrm{Au}(111)$ thin film on mica as a substrate. STM images were then acquired under ambient conditions (see Methods and SI).
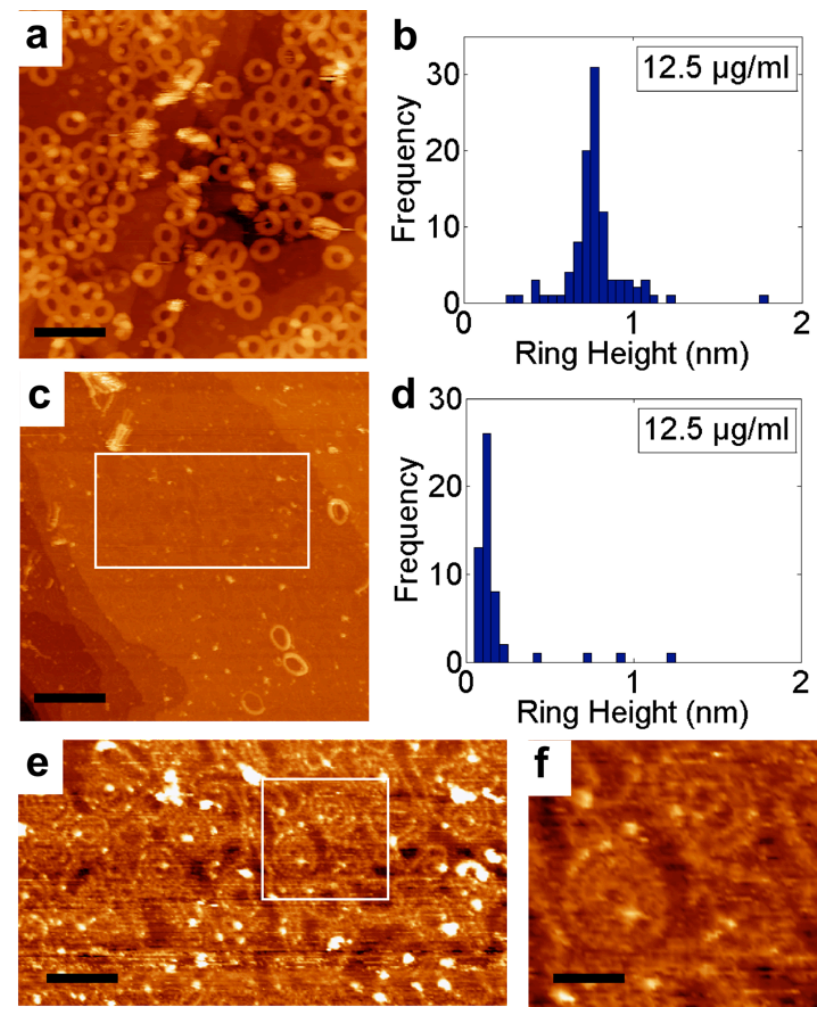

Figure 5. c-P30 deposited on $\mathrm{Au}(111)$ from solution (concentration $12.5 \mu \mathrm{g} / \mathrm{ml}$ ): (a) stacked nanorings deposited from a toluene:methanol 3:5 mixture; (b) histogram of heights showing triple stacked nanorings; (c) single-height nanorings deposited from toluene; (d) histogram of heights showing a peak at $\sim 0.1 \mathrm{~nm}$ corresponding to single-height nanorings; (e) zoomed image of highlighted area in (c) showing disordered arrangement of single-height c-P30; (f) further zoom of highlighted area in (e) showing nested structures. Scale bars: (a) $36 \mathrm{~nm}$; (c) $36 \mathrm{~nm}$ (e) $18 \mathrm{~nm}$; (f) $8 \mathrm{~nm}$.

In Fig. $5 \mathrm{a} \quad(12.5 \mu \mathrm{g} / \mathrm{mL}$ of $\boldsymbol{c}$-P30 in $5: 3$ methanol:toluene) we see many bright nanorings with lateral dimensions $\sim 13 \mathrm{~nm}$, close to the value expected for $\boldsymbol{c}$-P30. Many of the nanorings are slightly distorted from a circular shape and there are regions where partially- ordered nanorings form a quasi-close packed hexagonal arrangement. A histogram of the heights of the nanorings in this image (Fig. 5b) shows a clear peak around $0.7 \mathrm{~nm}$ corresponding to a height of three stacked nanorings.

In contrast, deposition from a solution of $\boldsymbol{c}$-P30 $(12.5 \mu \mathrm{g} / \mathrm{mL})$ in toluene (which is not compatible with electrospray) shows very few stacked nanorings (Fig. 5c). Under these conditions, we see single-height rings with a highly non-circular shape which form a disordered arrangement (Fig. 5e). A histogram (Fig. 5d) shows a clear peak at a height of $\sim 0.1 \mathrm{~nm}$ confirming the predominance of single-height structures. These results confirm the dominant role of solvent in the stacking, and demonstrate that this effect is not limited to electrospray deposition.

For the surfaces prepared from toluene:methanol (3:5) we do not observe any nested structures (see Fig. $5 \mathrm{a}, \mathrm{b})$ and the triple height stacks are stable under STM imaging. The majority of nanorings ( $>90 \%$ ) are incorporated within the near-circular triple height stacks discussed above, with the remainder in less ordered, in many cases overlapping, structures. Thus, stacking occurs for both solution and electrospray deposition, but the combination of stacking and nesting is only observed using electrospray. This implies that the stacks are preformed in the methanol:toluene solution consistent with previous work. However, the nesting observed using methanol:toluene depends on the method of deposition, and is therefore likely formed on adsorption rather than in solution. Noting that in almost all cases the nesting observed for electrospray deposition involves double-insingle, or single-in-double structures, we propose that these arrangements originate from triple stacks of nanorings which are formed in solution and then relax through rearrangement when they impinge on the surface. In the light of this discussion we also interpret many of the complex structures of overlapping nanorings, for example in Fig. 4c, as multiple (commonly triple) stacks which impinge on the sample in electrospray deposition and partially collapse into slipped stacks or nested arrangements. In contrast, there are far fewer partially collapsed structures on solution deposition from toluene/methanol (Fig. 5a); stacking is retained under these conditions.

We now consider whether stacking is required as a precursor to the formation of the nested arrangement. This is addressed in Fig. 5c-f which shows the surface after deposition from toluene. Under these conditions stacking is almost completely suppressed and we observe a disordered array of single-height nanorings (Fig. 5e). Importantly, the bending coefficient of single height rings is much lower (by a factor 3) than that of triple stacks, and so they are much more flexible resulting in a highlydeformed non-circular conformation. Nested structures are observed under these conditions (Fig. 5f) and our images show that the enclosed nanorings have a similar conformation of three hairpin bends to that observed for electrospray deposition under UHV. However, a significant difference is that for solution-phase deposition we only observe nested structures in which both the inner and outer nanoring are single-height. The absence of any combinations of double- and single-height nesting, similar to those observed for electrospray conditions, provides 
further evidence that the formation of such structures requires solvent-induced stacking as proposed above. We typically observe $\sim 8$ single-in-single nested structures in a $100 \mathrm{~nm} \times 100 \mathrm{~nm}$ image on surfaces such as that shown in Fig. 5e, and $\sim 10 \%$ of the surface is covered with nanorings adsorbed in nested arrangements. However, due to the flexibility of the single height nanorings there are no clear examples of near-circular 'empty' nanorings which might accommodate a coiled nested structure; the only nanorings which have a near-circular conformation in Fig. 5e serve as the outer ring of a nested structure.

As we show above in equation (1), a simple argument leads to a critical value of $N \approx 29$ for which nesting would be sterically permitted, consistent with our observations (and also the absence of nesting for $N=24$, the next smallest nanoring synthesised to date). However, the available area in the $\boldsymbol{c}$-P30 nested structures is less than the maximum assumed in deriving this simple rule since the outer nanoring is not perfectly circular. Interestingly, although the single-height nested nanorings, $B$ and $C$, have a conformation which, overall, is very similar to the double-height nested ring, there are also bright features identified by arrows in Fig. 4f. We attribute these features to small sections where the nested nanoring adopts a conformation where, locally, the porphyrin groups are either non-parallel to the substrate, or there is a region of self-overlapping; this may be a route to accommodate the single nanoring in a nested structure even for cases where the available area is marginally lower than the critical size estimated above.

\section{Conclusion}

We have shown that Vernier-template directed synthesis can be extended to provide access to large cyclic polymers. The porphyrin nanorings $\boldsymbol{c}$-P30, $\boldsymbol{c}$-P40 and $\boldsymbol{c - P 5 0}$ are the largest monodisperse covalent synthetic macrocycles yet reported, with carbocyclic topologies of up to $750 \mathrm{C}-\mathrm{C}$ bonds. These cyclic polymers are highly amenable for imaging by STM, both under UHV, when deposited by electrospray, and under ambient conditions, deposited from solution. These STM experiments reveal that the larger rings, with 30 or more repeat units, form nested complexes, with one nanoring molecule folded inside another circular nanoring. Supramolecular nesting was observed under both UHV and solution-phase conditions. Under UHV, nesting is frequently combined with stacking, so that a stack of folded molecules sits inside a single-height extended ring, or such that a single folded molecule sits inside a stack of two extended ring molecules. The statistical distribution of these stacked/nested assemblies strongly suggests that they are formed, under UHV electrospray conditions, by the onsurface rearrangement of triple-decker nanoring stacks. This work illustrates the tendency for large macrocyclic molecules to undergo biomimetic self-assembly, and the power of STM for probing supramolecular processes.

\section{Methods}

Vernier-templated polymerisation of $\boldsymbol{l}$-P10 in the presence of T6. The template T6 $(0.68 \mathrm{mg}, 0.68 \mu \mathrm{mol})$ and the linear porphyrin 10 -mer $\boldsymbol{l}$-P10 $(4.7 \mathrm{mg}, 0.41 \mu \mathrm{mol})$ were dissolved in $\mathrm{CHCl}_{3}(5.0 \mathrm{~mL})$ and heated at $50{ }^{\circ} \mathrm{C}$ until clear solution formed. A catalyst solution was prepared by dissolving $\mathrm{Pd}\left(\mathrm{PPh}_{3}\right)_{2} \mathrm{Cl}_{2}$
(1.0 mg, $1.4 \mu \mathrm{mol})$, $\mathrm{CuI}(1.2 \mathrm{mg}, 6.9 \mu \mathrm{mol})$ and 1,4benzoquinone $(3.0 \mathrm{mg}, 28 \mu \mathrm{mol})$ in $\mathrm{CHCl}_{3}(700 \mu \mathrm{L})$ and $i-\mathrm{Pr}_{2} \mathrm{NH}(60 \mu \mathrm{L}) .250 \mu \mathrm{L}$ of the catalysts solution was added to a solution of $\boldsymbol{l}$-P10 and T6 at $0{ }^{\circ} \mathrm{C}$ and then stirred at $0{ }^{\circ} \mathrm{C}$ for 2 hours and then at $20^{\circ} \mathrm{C}$ for 12 hours. The porphyrin oligomers mixture was separated from the catalysts by size-exclusion chromatography (Biobeads $\mathrm{SX}-1, \mathrm{CHCl}_{3} / 10 \%$ pyridine) and further separated by recycling gel permeation chromatography to yield $\boldsymbol{c}$-P10 (1.2 mg, 26\%), $\boldsymbol{c}$-P20 (0.8 mg, $17 \%), \boldsymbol{c}$-P30 (1.2 $\mathrm{mg}, 26 \%)$ and $\boldsymbol{c}$-P40 (0.5 $\mathrm{mg}, 11 \%)$.

Scanning tunnelling microscopy: (i) UHV experiments - a solution of $\boldsymbol{c}$-P10, $\boldsymbol{c}$-P20, $\boldsymbol{c}$-P30, $\boldsymbol{c}$-P40 or $\boldsymbol{c}$-P50 in toluenemethanol (3:1 by volume; concentration, $100 \mu \mathrm{m} \mathrm{mL}^{-1}$ ) was deposited on the substrate (gold on mica) by electrospray. Images were acquired in ultrahigh vacuum using electrochemically etched tungsten tips, in constant-current mode at room temperature; (ii) the samples in Fig. 5 were prepared by immersing a gold on mica substrate in a solution for 10 minutes. Further details are included in the SI.

\section{References}

1. Hunter, C. A. \& Anderson, H. L. What is cooperativity? Angew. Chem. Int. Ed. 48, 7488-7499 (2009).

2. Cheng, R. P. Beyond de novo protein design - de novo design of non-natural folded oligomers. Current Opinion Struct. Biol. 14, 512-520 (2004).

3. Gan, Q., Ferrand, Y., Bao, C., Kauffmann, B., Grélard, A., Jiang, H. \& Huc, I. Helix-rod host-guest complexes with shuttling rates much faster than disassembly. Science 331, 1172-1175 (2011).

4. Sakai, N., Mareda, J. \& Matile, S. Artificial $\beta$-barrels. Acc. Chem. Res. 41, 1354-1365 (2008).

5. Kondratuk, D. V., Perdigao, L. M. A., O'Sullivan, M. C., Svatek, S., Smith, G., O’Shea, J. N., Beton, P. H. \& Anderson, H. L. Two Vernier-templated routes to a 24porphyrin nanoring. Angew. Chem. Int. Ed. 51, 6696-6699 (2012).

6. Bartels, L. Tailoring molecular layers at metal surfaces. Nat. Chem. 2, 87-95 (2010).

7. Kudernac, T., Lei, S., Elemans, J. A. A. W. \& De Feyter, S. Two-dimensional supramolecular self-assembly: nanoporous networks on surfaces. Chem. Soc. Rev. 38, 402421 (2009).

8. Barth, J. V, Costantini, G. \& Kern, K. Engineering atomic and molecular nanostructures at surfaces. Nature 437, 671679 (2005).

9. Böhringer, M. et al. Two-dimensional self-assembly of supramolecular clusters and chains. Phys. Rev. Lett. 1, 324327 (1999).

10. Yokoyama, T., Yokoyama, S., Kamikado, T., Okuno, Y. \& Mashiko, S. Selective assembly on a surface of supramolecular aggregates with controlled size and shape. Nature 413, 619-621 (2001).

11. Barth, J. V et al. Building supramolecular nanostructures at surfaces by hydrogen bonding. Angew. Chem. Int. Ed. 39, 1230-1234 (2000).

12. Griessl, S., Lackinger, M., Edelwirth, M., Hietschold, M. \& Heckl, W. M. Self-assembled two-dimensional molecular host-guest architectures from trimesic acid. Single Mol. 3 , 25-31 (2002).

13. Theobald, J. A., Oxtoby, N. S., Phillips, M. A., Champness, N. R. \& Beton, P. H. Controlling molecular deposition and layer structure with supramolecular surface assemblies. Nature 424, 1029-31 (2003).

14. Stepanow, S. et al. Steering molecular organization and host-guest interactions using two-dimensional nanoporous coordination systems. Nat. Mater. 3, 229-33 (2004). 
15. Griessl, S. J. H. et al. Incorporation and manipulation of coronene in an organic template structure. Langmuir $\mathbf{2 0}$, 9403-7 (2004).

16. Blunt, M. O. et al. Guest-induced growth of a surface-based supramolecular bilayer. Nat. Chem. 3, 74-8 (2011).

17. Spillmann, H. et al. Hierarchical assembly of twodimensional homochiral nanocavity arrays. J. Am. Chem. Soc. 125, 10725-8 (2003).

18. Furukawa, S. et al. Structural transformation of a twodimensional molecular network in response to selective guest inclusion. Angew. Chem. Int. Ed. 46, 2831-2834 (2007).

19. Nath, K. G. et al. Rational modulation of the periodicity in linear hydrogen-bonded assemblies of trimesic acid on surfaces. J. Am. Chem. Soc. 128, 4212-4213 (2006).

20. Klappenberger, F. et al. Conformational adaptation in supramolecular assembly on surfaces. ChemPhysChem $\mathbf{8}$, 1782-1786 (2007).

21. Jung, T. A., Schlittler, R. R. \& Gimzewski, J. K. Conformational identification of individual adsorbed molecules with the STM. Nature 386, 696-698 (1997).

22. Taylor, P. N., Huuskonen, J., Rumbles, G., Aplin, R. T., Williams, E. \& Anderson, H. L. Conjugated porphyrin oligomers from monomer to hexamer. Chem. Commun. 909-910 (1998).

23. Sprafke, J. K. et al. Belt-shaped $\pi$-systems: relating geometry to electronic structure in a six-porphyrin nanoring. J. Am. Chem. Soc. 133, 17262-17273 (2011).

24. Saywell, A., Sprafke, J. K., Esdaile, L. J., Britton, A. J., Rienzo, A., Anderson, H. L., O'Shea, J. N. \& Beton, P. H. Conformation and packing of porphyrin polymer chains deposited using electrospray on a gold surface. Angew. Chem. Int. Ed. 49, 9136-9139 (2010).

25. O'Sullivan, M. C., Sprafke, J. K., Kondratuk, D. V., Rinfray, C., Claridge, T. D. W., Saywell, A., Blunt, M. O., O'Shea, J. N., Beton, P. H., Malfois, M. \& Anderson, H. L. Vernier templating and synthesis of a 12-porphyrin nanoring. Nature 469, 72-75 (2011).

26. Svatek, S. A., Perdigão, L. M. A., Stannard, A., Wieland, M. B., Kondratuk, D. V., Anderson, H. L., O'Shea, J. N. \& Beton, P. H. Mechanical stiffening of porphyrin nanorings through supramolecular columnar stacking. Nano Lett, 13, 3391-3395 (2013).

27. Wieland, M. B. et al. Height dependent molecular trapping in stacked cyclic porphyrin nanorings. Chem. Commun. 50, 7332-7335 (2014).

28. Bielawski, C. \& Grubbs, R. H. Living ring-opening metathesis polymerization. Prog. Pol. Sci. 32, 1-29 (2007).

29. Semlyen, J. A., "Cyclic Polymers", Kluwer Academic, $2^{\text {nd }}$ ed. (2000).

30. Jia, Z. \& Monteiro, M. J. Cyclic polymers: methods and strategies. J. Pol. Scie. Pol. Chem. 50, 2085-2097 (2012).

31. Mayor, M. \& Didschies, C. A giant conjugated molecular ring. Angew. Chem. Int. Ed. 42, 3176-3179 (2003).

32. Aggarwal, A. V. et al. Fluctuating exciton localizations in giant $\pi$-conjugated spoked-wheel macrocycles. Nature Chem. 5, 964-970 (2013).

33. Hori, T., Peng, X., Aratani, N., Takagi, A., Matsumoto, T., Kawai, T., Yoon, Z. S., Yoon, M.-C., Yang, J., Kim, D. \&
Osuka, A. Synthesis of nanometer-scale porphyrin wheels of variable size. Chem. Eur. J. 14, 582-595 (2008).

34. Hoffmann, M., Kärnbratt, J., Chang, M.-H., Herz, L. M., Albinsson, B. \& Anderson, H. L. Enhanced $\pi$-conjugation around a porphyrin [6]nanoring. Angew. Chem. Int. Ed. 47, 4993-4996 (2008).

35. Hoffmann, M., Wilson, C. J., Odell, B. \& Anderson H. L. Template-directed synthesis of a $\pi$-conjugated porphyrin nanoring. Angew. Chem. Int. Ed. 46, 3122-3125 (2007).

36. Mahabadi, H. K. \& Rudin, A. Effect of solvent on concentration dependence of hydrodynamic volumes and GPC elution volumes. Pol. J. 11, 123-131 (1979).

37. Grubisic, Z., Rempp, P. \& Benoit, H. A universal calibration for gel permeation chromatography. J. Polym. Sci. B Pol. Lett. 5, 753-759 (1967).

38. Fukatsu, M. \& Kurata, M. Hydrodynamic properties of flexible ring macromolecules. J. Chem. Phys. 44, 45394545 (1966).

39. Dodgson, K. \& Semlyen, J. A. Studies of cyclic and linear poly(dimethylsiloxanes): 1 . Limiting viscosity numbermolecular weight relationships. Polymer 18, 1265-1268 (1977).

40. Kricheldorf, H. R. Cyclic polymers: synthetic strategies and physical properties. J. Polym. Sci. Part A: Polym. Chem. 48, 251-284 (2010).

41. Brede, J. et.al. Dynamics of molecular self-ordering in tetraphenyl porphyrin monolayer on metallic substrates. Nanotechnology 20275602 (2009).

\section{Acknowledgements}

We thank the Engineering and Physical Sciences Research Council (EPSRC) and the Clarendon Fund for support; the EPSRC mass spectrometry service (Swansea) for mass spectra.

\section{Author contributions}

H.L.A. and D.V.K. designed the synthesis of cyclic polymers. P.H.B., L.M.A.P., J.N.O.S. and A.M.S.E. developed the protocols required for STM imaging. Synthesis and solutionphase characterisation were carried out by D.V.K. UHV and ambient STM experiments were carried out by L.M.A.P. and A.M.S.E. respectively. The manuscript was written by D.V.K., H.L.A. and P.H.B. All authors contributed towards data analysis and edited the manuscript.

\section{Additional information}

The authors declare no competing financial interests. Supplementary information accompanies this paper at www.nature.com/naturechemistry. Reprints and permission information is available online at http://www.nature.com/reprints. Correspondence and requests for materials should be addressed to H.L.A. or P.H.B.

\section{Competing financial interests}

The authors declare no competing financial interests. 


\section{Graphical abstract for table of contents:}
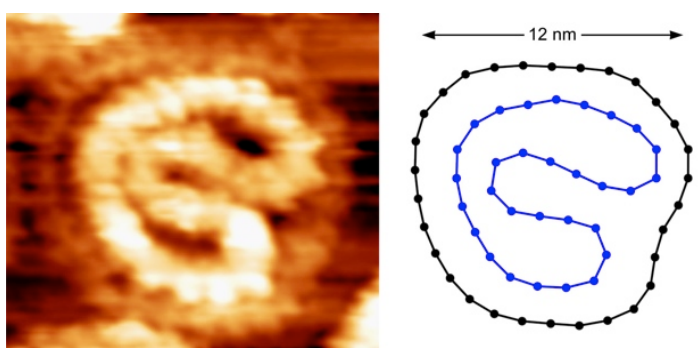


\section{Supplementary Information}

\section{Supramolecular nesting of cyclic polymers}

Dmitry V. Kondratuk, ${ }^{\dagger}$ Luís M. A. Perdigão ${ }^{\ddagger}$ Ayad M. S. Esmail, ${ }^{\ddagger}$ James N. O’Shea ${ }^{\ddagger}$ Peter H. Beton ${ }^{\ddagger *}$ and Harry L. Anderson ${ }^{\dagger *}$

${ }^{\dagger}$ Department of Chemistry, University of Oxford, Oxford, OX1 3TA, UK

${ }^{*}$ School of Physics \& Astronomy, University of Nottingham, Nottingham, NG7 2RD, UK

\section{Table of Contents}

A. Materials and Methods $\quad$ S2

$\begin{array}{lr}\text { B. Synthetic Procedures } & \text { S2 }\end{array}$

B1. Synthesis of linear porphyrin building blocks $\quad$ S2

Synthesis of $l$-P2 $2_{\text {THS,THS, }} \boldsymbol{l}$-P10 ${ }_{\text {THS,THS }}$ and $l$-P18 ${ }_{\text {THS,THS }}$

by coupling of $\boldsymbol{l}$-P8 and the excess of $\boldsymbol{l}$-P1 $\mathbf{1}_{\mathbf{H}, \mathbf{T H S}} \quad \mathrm{S} 3$

B2. Oligomerisation of $\boldsymbol{l}$-P10 $\quad$ S3

B2a. Full deprotection of $\boldsymbol{l}$-P10 ${ }_{\text {THS,THS }} \quad$ S3

B2b. Oligomerisation of $\boldsymbol{l}$-P10 in the absence of templates $\quad$ S3

B2c. Oligomerisation of $\boldsymbol{l}-\mathbf{P} 10$ in the presence of T6 $\quad$ S3

B2d. Oligomerisation of $\boldsymbol{l}$-P10 in the presence of T8 S4

$\begin{array}{ll}\text { C. Characterisation } & \text { S6 }\end{array}$

C1. Linear porphyrin 10-mer $\boldsymbol{l}$-P10 $\mathbf{T H S}_{\text {THS }} \quad$ S6

C1a. ${ }^{1}$ H-NMR analysis $\quad$ S6

C1b. MALDI-ToF $\quad$ S6

C2. Linear porphyrin 10-mer $\boldsymbol{l}$-P18 THS,THS $_{\text {Th }}^{\text {S7 }}$

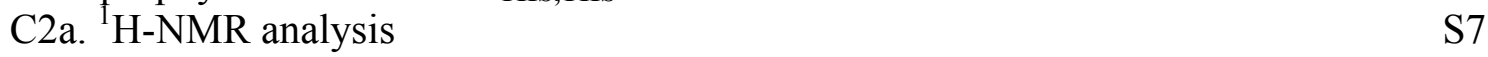

$\begin{array}{ll}\text { C2b. MALDI-ToF } & \text { S7 }\end{array}$

$\begin{array}{ll}\text { C3. Cyclic porphyrin 10-mer } \boldsymbol{c}-\mathbf{P 1 0} & \text { S8 }\end{array}$

C3a. ${ }^{1} \mathrm{H}-\mathrm{NMR}$ analysis $\quad$ S8

C3b. MALDI-ToF $\quad$ S8

C4. Cyclic porphyrin 20-mer $\boldsymbol{c}$-P20 $\quad$ S9

C4a. ${ }^{1} \mathrm{H}-\mathrm{NMR}$ analysis $\quad$ S9

C4b. MALDI-ToF $\quad$ S9

C5. Cyclic porphyrin 30-mer $\boldsymbol{c}$-P30 $\quad$ S10

C5a. ${ }^{1} \mathrm{H}-\mathrm{NMR}$ analysis $\quad \mathrm{S} 10$

$\begin{array}{ll}\text { C5b. MALDI-ToF } & \text { S10 }\end{array}$

C6. Cyclic porphyrin 40-mer $\boldsymbol{c}-\mathbf{P 4 0} \quad$ S11

C6a. ${ }^{1} \mathrm{H}-\mathrm{NMR}$ analysis $\quad \mathrm{S} 11$

C6b. MALDI-ToF $\quad$ S11

C7. Cyclic porphyrin 50-mer $\boldsymbol{c}$-P50 $\quad$ S12

C7a. ${ }^{1} \mathrm{H}-\mathrm{NMR}$ analysis $\quad \mathrm{S} 12$

$\begin{array}{ll}\text { C7b. MALDI-ToF } & \text { S12 }\end{array}$

D. UV/Vis/NIR absorption of $\boldsymbol{c}$-P10, $\boldsymbol{c}$-P20, $\boldsymbol{c}$-P30 and $\boldsymbol{c}$-P40

$\begin{array}{ll}\text { E. Scanning tunnelling microscopy } & \mathrm{S} 13\end{array}$

$\begin{array}{ll}\text { E1. Preparation and imaging of gold surface } & \text { S13 }\end{array}$

E2. Electrospray deposition $\quad \mathrm{S} 13$

E3. Image of linear oligomer $\boldsymbol{l}$-P4 $\quad$ S13

E4. Additional images of $\boldsymbol{c}-\mathbf{P 1 0}, \boldsymbol{c}-\mathbf{P 2 0}, \boldsymbol{c}-\mathbf{P 3 0}$ and $\boldsymbol{c}-\mathbf{P 4 0} \quad \mathrm{S} 14$

E5. Additional images of $\boldsymbol{c}$-P50 $\quad$ S15

E6. Height profiles of nested and stacked nanorings $\quad$ S16

$\begin{array}{ll}\text { F. References } & \text { S17 }\end{array}$ 


\section{A. Materials and Methods}

Dry $\mathrm{CHCl}_{3}, \mathrm{CH}_{2} \mathrm{Cl}_{2}$ and toluene were obtained by passing through alumina under $\mathrm{N}_{2}$ pressure. All other reagents were used as commercially supplied. NMR data were collected at $500 \mathrm{MHz}$ using a Bruker AVII 500 or DRX 500 or at $400 \mathrm{MHz}$ using a Bruker DPX 400 at $298 \mathrm{~K}$. Chemical shifts are quoted as parts per million (ppm) relative to residual $\mathrm{CHCl}_{3}$ at $\delta 7.27 \mathrm{ppm}$ and coupling constants $(J)$ are reported in Hertz. MALDI-ToF spectra were measured at the EPSRC National Mass Spectrometry service (Swansea) using the Applied Biosystems Voyager DE-STR. Room temperature UV-vis-NIR absorbance measurements were recorded with a Perkin-Elmer Lambda 20 photospectrometer. Size exclusion chromatography (SEC) was carried out using Bio-Beads S-X1, 200-400 mesh (Bio Rad). Analytical and semi-preparative GPC was carried out on Shimadzu Recycling GPC system equipped with LC-20 AD pump, SPD-20A UV detector and a set of JAIGEL $3 \mathrm{H}(20 \times 600 \mathrm{~mm})$ and JAIGEL $4 \mathrm{H}(20 \times 600 \mathrm{~mm})$ columns in toluene $/ 1 \%$ pyridine as eluent with a flow rate of $3.5 \mathrm{~mL} / \mathrm{min}$.

\section{B. Synthetic Procedures}

Half and fully-deprotected porphyrin monomer $\boldsymbol{l}$-P1 $\mathbf{H}_{\mathbf{H}, \mathbf{T H S}}$ and $\boldsymbol{l}$-P1 ${ }^{\mathrm{S} 1}$, fully-deprotected dimer $\boldsymbol{l}-\mathbf{P 2} \mathbf{2}^{\mathrm{S} 1}$, fully-deprotected trimer $\boldsymbol{l}-\mathbf{P 3} 3^{\mathrm{S} 2}$, fully-deprotected octamer $\boldsymbol{l}-\mathbf{P 8}{ }^{\mathrm{S} 3}$, pentadentate template $\mathbf{T 5}^{\mathrm{S} 4}$, hexadentate template $\mathbf{T 6}^{\mathrm{S} 2}$ and octadentate template $\mathbf{T 8}^{\mathrm{S} 5}$ were synthesised using published procedures or adopting them. The $\mathrm{Pd} / \mathrm{Cu}$ co-catalyst system with 1,4-benzoquinone as an oxidant was used throughout for homocoupling. ${ }^{\mathrm{S} 6}$

\section{B1. Synthesis of linear porphyrin building blocks}

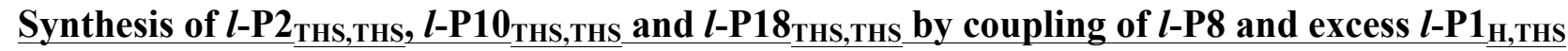

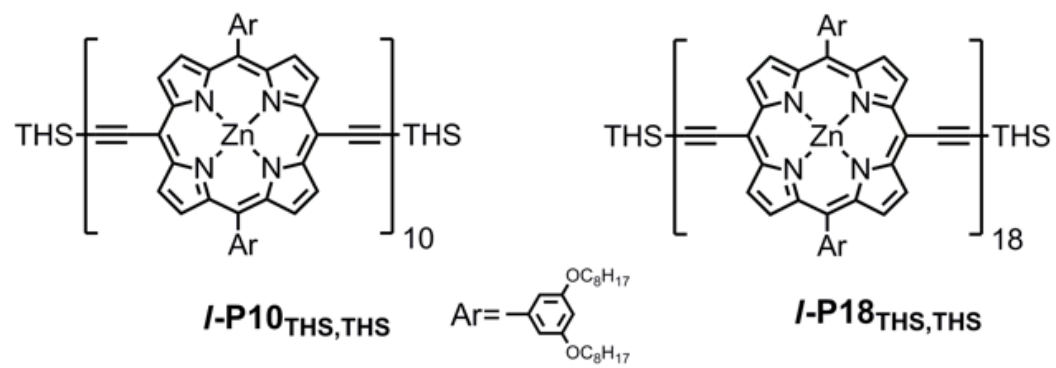

Fully-protected linear porphyrin 8 -mer $\boldsymbol{l}$-P8 $\mathbf{T H S}$,THS $(54.0 \mathrm{mg}, 5.8 \mu \mathrm{mol})$ was dissolved in $\mathrm{CH}_{2} \mathrm{Cl}_{2}$ $(30.0 \mathrm{~mL})$ and the solution degassed. Tetra- $n$-butylammonium fluoride $(1.0 \mathrm{M}$ in THF, $160 \mu \mathrm{L}$, $0.16 \mathrm{mmol}$ ) was added and the reaction mixture stirred at $20^{\circ} \mathrm{C}$ for $1 \mathrm{~h}$. under $\mathrm{N}_{2}$ atmosphere. The reaction was quenched with $\mathrm{MeOH}(1.0 \mathrm{~mL})$, the volume reduced, the $\boldsymbol{l}$-P8 precipitated with $\mathrm{MeOH}$ $(50 \mathrm{~mL})$, filtered off and dried in high vacuum. All obtained $\boldsymbol{l}$-P8 and half-deprotected porphyrin monomer $\boldsymbol{l}$-P1 $\mathbf{1}_{\mathbf{H}, \mathbf{T H S}}(308 \mathrm{mg}, 0.225 \mathrm{mmol})$ were dissolved in the mixture of toluene $(100 \mathrm{~mL})$ and pyridine $(1.0 \mathrm{~mL})$. A catalyst solution was prepared by dissolving dichlorobis(triphenylphosphine)palladium(II) (107 mg, $0.152 \mathrm{mmol})$, copper(I) iodide $(263.3 \mathrm{mg}, 1.38 \mathrm{mmol})$ and 1,4benzoquinone $(248.8 \mathrm{mg}, 2.30 \mathrm{mmol})$ in the mixture of toluene $(80.0 \mathrm{~mL})$ and freshly distilled $i-\operatorname{Pr}_{2} \mathrm{NH}(18.0 \mathrm{~mL})$ and added to the solution of $\boldsymbol{l}$-P8 and $\boldsymbol{l}$-P1 $\mathbf{1}_{\mathbf{H}, \mathbf{T H S}}$. The reaction mixture was stirred at $20{ }^{\circ} \mathrm{C}$ for $3 \mathrm{~h}$, after which half of the initial amount of the catalyst solution was added and the mixture stirred at $60{ }^{\circ} \mathrm{C}$ for $2 \mathrm{~h}$. Once UV-Vis spectroscopy showed no changes, the reaction mixture was passed through short silica column $\left(\mathrm{CHCl}_{3} / 1 \%\right.$ pyridine $)$ to remove the catalysts and then over a size exclusion column (Biobeads SX-1 in toluene/1\% pyridine) to remove the 1,4benzoquinone. Preparative GPC (toluene $10 \%$ pyridine) followed by the recycling GPC yielded 242

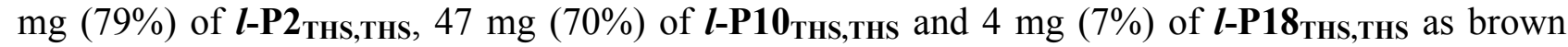
solids. 
l-P10 ThS,Ths: $^{1} \mathrm{H}-\mathrm{NMR}\left(400 \mathrm{MHz}, \mathrm{CDCl}_{3} / 1 \% d_{5}\right.$-pyridine): $\delta_{\mathrm{H}} 9.77-9.73\left(\mathrm{~m}, 36 \mathrm{H},-\mathrm{Ar} H_{\mathrm{\beta}}\right), 9.54(\mathrm{~d}$, $\left.4 \mathrm{H}, J=4.5 \mathrm{~Hz},-\mathrm{Ar} H_{\beta}\right), 8.96-8.93\left(\mathrm{~m}, 36 \mathrm{H},-\operatorname{Ar} H_{\mathrm{\beta}}\right), 8.84\left(\mathrm{~d}, 4 \mathrm{H}, J=4.4 \mathrm{~Hz},-\mathrm{Ar} H_{\beta}\right), 7.28-7.21(\mathrm{~m}$, 40H, Ar- $\left.H_{\text {ortho }}\right), 6.80-6.77$ (m, 20H, Ar- $\left.H_{\text {para }}\right), 3.99$ (m, 80H, - $\left.\mathrm{OCH}_{2}\right), 1.76-1.67$ (m, 92H, -CH $\mathrm{CH}_{2}$, $1.65-1.59\left(\mathrm{~m}, 12 \mathrm{H},-\mathrm{CH}_{2}\right), 1.42-1.07\left(\mathrm{~m}, 424 \mathrm{H},-\mathrm{CH}_{2}\right), 0.89-0.85\left(\mathrm{~m}, 12 \mathrm{H},-\mathrm{CH}_{2}\right), 0.74-0.66(\mathrm{~m}$, $\left.138 \mathrm{H}, \quad-\mathrm{CH}_{3}\right) ; \quad m / z \quad$ (MALDI-ToF) $11419 \quad\left(\mathrm{C}_{716} \mathrm{H}_{898} \mathrm{~N}_{40} \mathrm{O}_{40} \mathrm{Zn}_{10}, \quad \mathrm{M}^{+}\right.$requires 11415$) ; \lambda_{\max }$ $\left(\mathrm{CHCl}_{3} / 1 \%\right.$ pyridine $) / \mathrm{nm}(\log \varepsilon) 469$ (6.01), 591 (4.91), 809 (5.73).

l-P18 ThS,THs: $^{1} \mathrm{H}-\mathrm{NMR}\left(400 \mathrm{MHz}, \mathrm{CDCl}_{3} / 1 \% d_{5}\right.$-pyridine): $\delta_{\mathrm{H}} 9.74-9.70\left(\mathrm{~m}, 68 \mathrm{H},-\mathrm{Ar} H_{\mathrm{\beta}}\right), 9.51(\mathrm{~d}$, $\left.4 \mathrm{H}, J=4.5 \mathrm{~Hz},-\mathrm{Ar} H_{\mathrm{\beta}}\right), 8.93-8.89\left(\mathrm{~m}, 68 \mathrm{H},-\mathrm{Ar} H_{\mathrm{\beta}}\right), 8.81\left(\mathrm{~d}, 4 \mathrm{H}, J=4.5 \mathrm{~Hz},-\operatorname{Ar} H_{\beta}\right), 7.23-7.17(\mathrm{~m}$, $\left.72 \mathrm{H}, \mathrm{Ar}-H_{\text {ortho }}\right), 6.77-6.75\left(\mathrm{~m}, 36 \mathrm{H}, \mathrm{Ar}-\mathrm{H}_{\text {para }}\right), 3.94\left(\mathrm{~m}, 144 \mathrm{H},-\mathrm{OCH}_{2}\right), 1.71-1.64\left(\mathrm{~m}, 156 \mathrm{H},-\mathrm{CH}_{2}\right)$, 1.61-1.55 (m, 12H, - $\left.\mathrm{CH}_{2}\right), 1.35-0.99\left(\mathrm{~m}, 774 \mathrm{H},-\mathrm{CH}_{2}\right), 0.85-0.80\left(\mathrm{~m}, 12 \mathrm{H},-\mathrm{CH}_{2}\right), 0.70-0.60(\mathrm{~m}$, $\left.234 \mathrm{H},-\mathrm{CH}_{3}\right) ; \mathrm{m} / \mathrm{z}$ (MALDI-ToF) $20181 \quad\left(\mathrm{C}_{1260} \mathrm{H}_{1554} \mathrm{~N}_{72} \mathrm{O}_{72} \mathrm{Zn}_{18}, \mathrm{M}^{+}\right.$requires 20093); $\lambda_{\max }$ $\left(\mathrm{CHCl}_{3} / 1 \%\right.$ pyridine $) / \mathrm{nm}(\log \varepsilon) 471$ (6.33), 592 (5.22), 815 (6.13).

\section{B2. Oligomerisation of $\mathbf{l}-\mathbf{P 1 0}$}

\section{B2a. Full deprotection of $l$-P10}

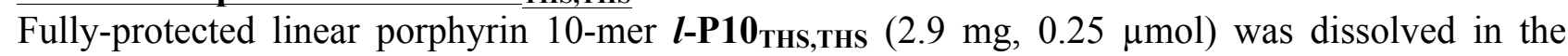
mixture of $\mathrm{CH}_{2} \mathrm{Cl}_{2}(0.5 \mathrm{~mL})$ and pyridine $(0.5 \mu \mathrm{L})$ and the solution degassed. Tetra- $n$ butylammonium fluoride (1.0 M in THF, $2 \mu \mathrm{L}, 2 \mu \mathrm{mol})$ was added and the reaction mixture stirred at $20{ }^{\circ} \mathrm{C}$ for $20 \mathrm{~min}$ under $\mathrm{N}_{2}$ atmosphere. The reaction was quenched with $\mathrm{MeOH}(10 \mu \mathrm{L})$, the volume reduced, the $\boldsymbol{l}$-P10 precipitated with $\mathrm{MeOH}(5 \mathrm{~mL})$, filtered out and dried in high vacuum and used further without characterisation.

\section{B2b. Oligomerisation of $\boldsymbol{l}$-P10 in the absence of templates}

The oligomerisation of $\boldsymbol{l}$-P10 in the absence of templates was carried out without separation of products to obtain only their distribution. The authenticity of the products was confirmed by comparison of corresponding retention times (Fig. 2a of the main text).

\section{B3c. Oligomerisation of $l$-P10 in the presence of T6}
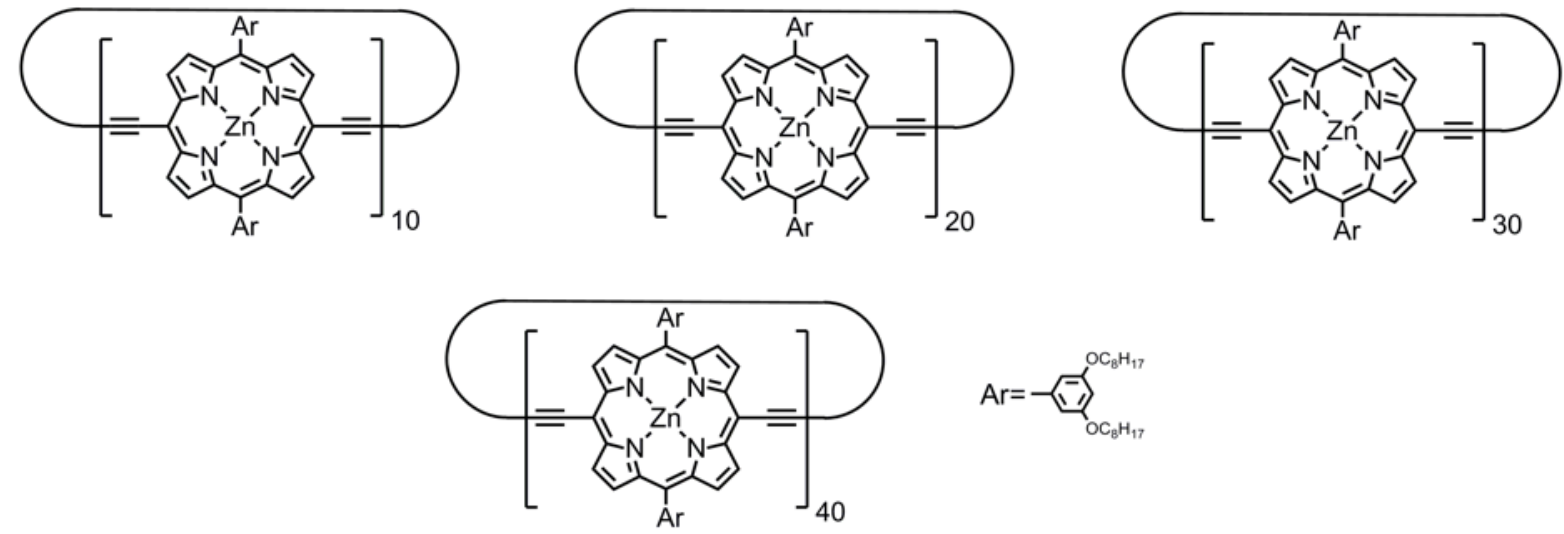

The template T6 $(0.68 \mathrm{mg}, 0.68 \mu \mathrm{mol})$ and the linear porphyrin 10 -mer $\boldsymbol{l}$-P10 $(4.7 \mathrm{mg}, 0.41 \mu \mathrm{mol})$ were dissolved in $\mathrm{CHCl}_{3}(5.0 \mathrm{~mL})$ and heated at $50{ }^{\circ} \mathrm{C}$ until clear solution formed. A catalyst solution was prepared by dissolving $\mathrm{Pd}\left(\mathrm{PPh}_{3}\right)_{2} \mathrm{Cl}_{2}(1.0 \mathrm{mg}, 1.41 \mu \mathrm{mol}), \mathrm{CuI}(1.2 \mathrm{mg}, 6.9 \mu \mathrm{mol})$ and 1,4-benzoquinone $(3.0 \mathrm{mg}, 27.9 \mu \mathrm{mol})$ in $\mathrm{CHCl}_{3}(700 \mu \mathrm{L})$ and $i$ - $\mathrm{Pr}_{2} \mathrm{NH}(60 \mu \mathrm{L}) .250 \mu \mathrm{L}$ of the catalysts solution was added to a solution of $\boldsymbol{l}$-P10 and T6 at $0{ }^{\circ} \mathrm{C}$ and then stirred at $0{ }^{\circ} \mathrm{C}$ for $2 \mathrm{~h}$. and then at $20{ }^{\circ} \mathrm{C}$ for $12 \mathrm{~h}$. Once analytical GPC confirmed full conversion of the $\boldsymbol{l}$-P10, the porphyrin oligomers mixture was separated from the catalysts by size-exclusion chromatography (Biobeads SX-1, $\mathrm{CHCl}_{3} / 10 \%$ pyridine) and further separated by recycling gel permeation chromatography (Fig. Sla) to yield $\boldsymbol{c}$-P10 (1.2 mg, 26\%), $\boldsymbol{c}$-P20 (0.8 mg, 17\%), $\boldsymbol{c}$-P30 (1.2 mg, $26 \%)$ and $c$-P40 (0.5 mg, 11\%).

c-P10: ${ }^{1} \mathrm{H}-\mathrm{NMR}\left(500 \mathrm{MHz}, \mathrm{CDCl}_{3} / 1 \% d_{5}\right.$-pyridine): $\delta_{\mathrm{H}} 9.74\left(\mathrm{~d}, 40 \mathrm{H}, J=4.5 \mathrm{~Hz},-\mathrm{Ar} H_{\mathrm{\beta}}\right), 8.96(\mathrm{~d}$, $\left.40 \mathrm{H}, J=4.5 \mathrm{~Hz},-\mathrm{Ar} H_{\mathrm{\beta}}\right), 7.29\left(\mathrm{~m}, 40 \mathrm{H}, \mathrm{Ar}-H_{\text {ortho }}\right), 6.84\left(\mathrm{~m}, 20 \mathrm{H}, \mathrm{Ar}-H_{\text {para }}\right), 4.07$ (s br, 80H, $\left.\mathrm{OCH}_{2}\right), 1.83-1.77\left(\mathrm{~m}, 80 \mathrm{H}, \mathrm{CH}_{2}\right), 1.46-1.40\left(\mathrm{~m}, 80 \mathrm{H}, \mathrm{CH}_{2}\right), 1.32-1.16\left(\mathrm{~m}, 320 \mathrm{H}, \mathrm{CH}_{2}\right), 0.82-0.74$ 
$\left(\mathrm{m}, 120 \mathrm{H},-\mathrm{CH}_{3}\right) ; \mathrm{m} / z$ (MALDI-ToF) $10852\left(\mathrm{C}_{680} \mathrm{H}_{820} \mathrm{~N}_{40} \mathrm{O}_{40} \mathrm{Zn}_{10}, \mathrm{M}^{+}\right.$requires 10848); $\lambda_{\max }$ $\left(\mathrm{CHCl}_{3} / 1 \%\right.$ pyridine $) / \mathrm{nm}(\log \varepsilon) 473$ (5.91), 595 (4.82), 808 (5.68).

c-P20: ${ }^{1} \mathrm{H}-\mathrm{NMR}\left(400 \mathrm{MHz}, \mathrm{CDCl}_{3} / 1 \% d_{5}\right.$-pyridine): $\delta_{\mathrm{H}} 9.80\left(\mathrm{~d}, 80 \mathrm{H}, J=4.5 \mathrm{~Hz},-\mathrm{Ar} H_{\mathrm{\beta}}\right), 8.96(\mathrm{~d}$, $\left.80 \mathrm{H}, J=4.5 \mathrm{~Hz},-\mathrm{Ar} H_{\mathrm{\beta}}\right), 7.28\left(\mathrm{~m}, 80 \mathrm{H}, \operatorname{Ar}-H_{\text {ortho }}\right), 6.85\left(\mathrm{~m}, 40 \mathrm{H}, \operatorname{Ar}-H_{\text {para }}\right), 4.07$ (s br, $160 \mathrm{H}$, $\left.\mathrm{OCH}_{2}\right), 1.81-1.78\left(\mathrm{~m}, 160 \mathrm{H}, \mathrm{CH}_{2}\right), 1.46-1.40\left(\mathrm{~m}, 160 \mathrm{H}, \mathrm{CH}_{2}\right), 1.31-1.12\left(\mathrm{~m}, 640 \mathrm{H}, \mathrm{CH}_{2}\right), 0.78-$ $0.74\left(\mathrm{~m}, 240 \mathrm{H},-\mathrm{CH}_{3}\right) ; \mathrm{m} / z$ (MALDI-ToF) $21701\left(\mathrm{C}_{1360} \mathrm{H}_{1640} \mathrm{~N}_{80} \mathrm{O}_{80} \mathrm{Zn}_{20}, \mathrm{M}^{+}\right.$requires 21696); $\lambda_{\max }$ $\left(\mathrm{CHCl}_{3} /\right.$ 1\% pyridine) / nm (log $\left.\varepsilon\right) 472$ (6.21), 594 (5.12), 813 (6.02).

c-P30: ${ }^{1} \mathrm{H}-\mathrm{NMR}\left(400 \mathrm{MHz}, \mathrm{CDCl}_{3} / 1 \% d_{5}\right.$-pyridine): $\delta_{\mathrm{H}} 9.78\left(\mathrm{~m}, 120 \mathrm{H},-\mathrm{Ar} H_{\mathrm{\beta}}\right), 8.98(\mathrm{~m}, 120 \mathrm{H},-$ $\left.\operatorname{Ar} H_{\mathrm{\beta}}\right), 7.28\left(\mathrm{~m}, 120 \mathrm{H}, \mathrm{Ar}-H_{\text {ortho }}\right), 6.83\left(\mathrm{~m}, 60 \mathrm{H}, \mathrm{Ar}-H_{\text {para }}\right), 4.03$ (s br, 240H, $\left.-\mathrm{OCH}_{2}\right), 1.76(\mathrm{~m}$, $\left.240 \mathrm{H}, \mathrm{CH}_{2}\right), 1.40\left(\mathrm{~m}, 240 \mathrm{H}, \mathrm{CH}_{2}\right), 1.25-1.10\left(\mathrm{~m}, 960 \mathrm{H}, \mathrm{CH}_{2}\right), 0.71\left(\mathrm{~m}, 360 \mathrm{H},-\mathrm{CH}_{3}\right) ; \mathrm{m} / z$ (MALDIToF) $32681\left(\mathrm{C}_{2040} \mathrm{H}_{2460} \mathrm{~N}_{120} \mathrm{O}_{120} \mathrm{Zn}_{30}, \mathrm{M}^{+}\right.$requires 32543$) ; \lambda_{\max }\left(\mathrm{CHCl}_{3} / 1 \%\right.$ pyridine $) / \mathrm{nm}(\log \varepsilon)$ 473 (6.43), 593 (5.33), 817 (6.27).

c-P40: ${ }^{1} \mathrm{H}-\mathrm{NMR}\left(400 \mathrm{MHz}, \mathrm{CDCl}_{3} / 1 \% d_{5}\right.$-pyridine): $\delta_{\mathrm{H}} 9.77\left(\mathrm{~m}, 160 \mathrm{H},-\mathrm{Ar} H_{\beta}\right), 8.98(\mathrm{~d}, 160 \mathrm{H},-$ $\left.\operatorname{Ar} H_{\mathrm{\beta}}\right), 7.28\left(\mathrm{~m}, 160 \mathrm{H}, \operatorname{Ar}-H_{\text {ortho }}\right), 6.80\left(\mathrm{~m}, 80 \mathrm{H}, \operatorname{Ar}-H_{\text {para }}\right), 3.99$ (s br, 320H, $\left.-\mathrm{OCH}_{2}\right), 1.72(\mathrm{~m}$, $\left.320 \mathrm{H}, \mathrm{CH}_{2}\right), 1.36\left(\mathrm{~m}, 320 \mathrm{H}, \mathrm{CH}_{2}\right), 1.23-1.07\left(\mathrm{~m}, 1280 \mathrm{H}, \mathrm{CH}_{2}\right), 0.70-0.67\left(\mathrm{~m}, 480 \mathrm{H},-\mathrm{CH}_{3}\right) ; \mathrm{m} / z$ (MALDI-ToF) $43475\left(\mathrm{C}_{2720} \mathrm{H}_{3280} \mathrm{~N}_{160} \mathrm{O}_{160} \mathrm{Zn}_{40}, \mathrm{M}^{+}\right.$requires 43391$) ; \lambda_{\max }\left(\mathrm{CHCl}_{3} / 1 \%\right.$ pyridine) / nm $(\log \varepsilon) 474$ (6.50), 593 (5.40), 819 (6.34).

\section{B2d. Oligomerisation of $l-\mathrm{P} 10$ in the presence of $\mathrm{T} 8$}
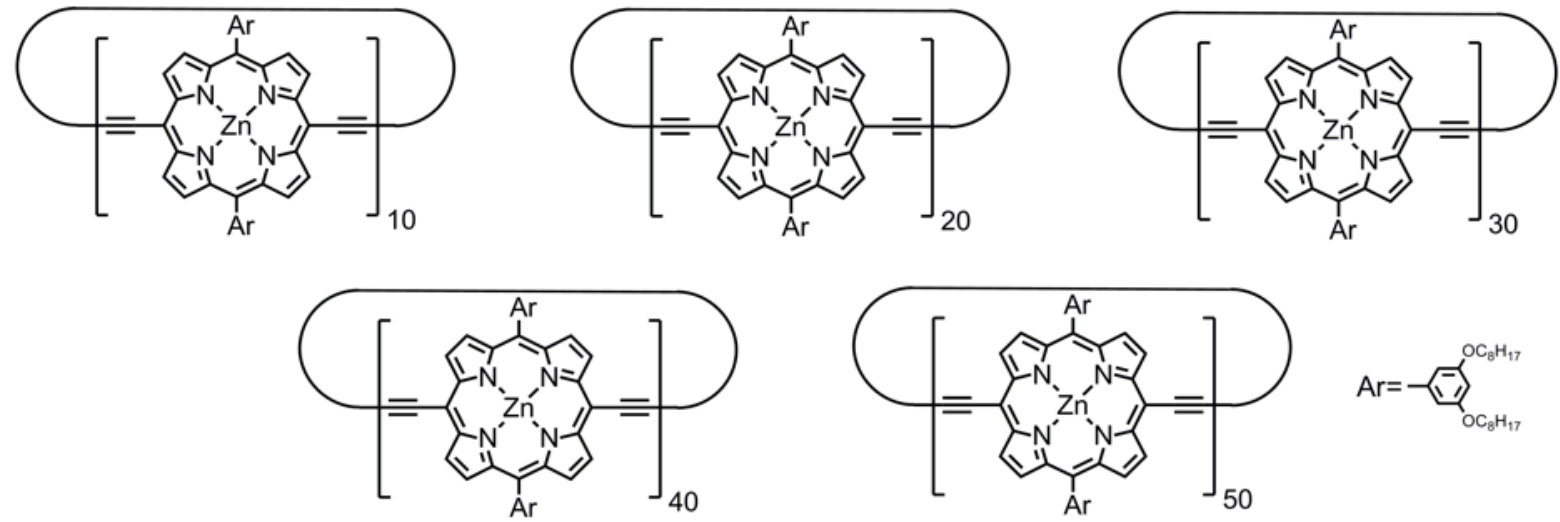

The template T8 $(0.98 \mathrm{mg}, 0.42 \mu \mathrm{mol})$ and the linear porphyrin 10 -mer $\boldsymbol{l}$-P10 $(4.5 \mathrm{mg}, 0.41 \mu \mathrm{mol})$ were dissolved in $\mathrm{CHCl}_{3}(5.3 \mathrm{~mL})$ and heated at $50{ }^{\circ} \mathrm{C}$ until clear solution formed. A catalyst solution was prepared by dissolving $\mathrm{Pd}\left(\mathrm{PPh}_{3}\right)_{2} \mathrm{Cl}_{2}(1.0 \mathrm{mg}, 1.41 \mu \mathrm{mol}), \mathrm{CuI}(1.2 \mathrm{mg}, 6.9 \mu \mathrm{mol})$ and 1,4-benzoquinone $(3.0 \mathrm{mg}, 27.9 \mu \mathrm{mol})$ in $\mathrm{CHCl}_{3}(700 \mu \mathrm{L})$ and $i$ - $\operatorname{Pr}_{2} \mathrm{NH}(60 \mu \mathrm{L}) .260 \mu \mathrm{L}$ of the catalysts solution was added to a solution of $\boldsymbol{l}$-P10 and $\mathbf{T 8}$ at $0{ }^{\circ} \mathrm{C}$ and then stirred at $0{ }^{\circ} \mathrm{C}$ for $2 \mathrm{~h}$ after which the initial amount of the catalysts solution was added and the mixture stirred at $0{ }^{\circ} \mathrm{C}$ for $2 \mathrm{~h}$ and then at $20^{\circ} \mathrm{C}$ for $10 \mathrm{~h}$. After that $1560 \mu \mathrm{L}$ of the catalyst solution was added in three equal portions - after $14 \mathrm{~h}$. of stirring and further stirred at $40{ }^{\circ} \mathrm{C}$, after $19 \mathrm{~h}$. of stirring and further stirred at $50{ }^{\circ} \mathrm{C}$ and after $17 \mathrm{~h}$. of stirring and further stirred at $50{ }^{\circ} \mathrm{C}$. Once analytical GPC confirmed full conversion of the $\boldsymbol{l}$-P10, the porphyrin oligomers mixture was separated from the catalysts by sizeexclusion chromatography (Biobeads $\mathrm{SX}-1, \mathrm{CHCl}_{3} / 10 \%$ pyridine) and further separated by recycling gel permeation chromatography (Fig. S1b) to yield $\boldsymbol{c}$-P10 $(0.3 \mathrm{mg}, 7 \%), \boldsymbol{c}$-P20 $(0.3 \mathrm{mg}$, 7\%), $\boldsymbol{c}$-P30 (0.7 mg, 16\%), $\boldsymbol{c}$-P40 (1.2 $\mathrm{mg}, 27 \%)$ and $\boldsymbol{c}$-P50 (0.6 mg, 13\%).

$c$-P10: ${ }^{1} \mathrm{H}-\mathrm{NMR}$ as reported above.

c-P20: ${ }^{1} \mathrm{H}-\mathrm{NMR}$ as reported above.

c-P30: ${ }^{1} \mathrm{H}-\mathrm{NMR}$ as reported above.

c-P40: ${ }^{1} \mathrm{H}-\mathrm{NMR}$ as reported above.

c-P50: ${ }^{1} \mathrm{H}-\mathrm{NMR}\left(400 \mathrm{MHz}, \mathrm{CDCl}_{3} / 1 \% d_{5}\right.$-pyridine): $\delta_{\mathrm{H}} 9.82\left(\mathrm{~m}, 200 \mathrm{H},-\mathrm{Ar} H_{\beta}\right), 9.01(\mathrm{~d}, 200 \mathrm{H}$, $\left.\operatorname{Ar} H_{\beta}\right), 7.34\left(\mathrm{~m}, 200 \mathrm{H}, \mathrm{Ar}-H_{\text {ortho }}\right), 6.86\left(\mathrm{~m}, 100 \mathrm{H}, \mathrm{Ar}-H_{\text {para }}\right), 4.06\left(\mathrm{~s} \mathrm{br}, 400 \mathrm{H},-\mathrm{OCH}_{2}\right), 1.81(\mathrm{~m}$, $\left.400 \mathrm{H}, \mathrm{CH}_{2}\right), 1.44\left(\mathrm{~m}, 400 \mathrm{H}, \mathrm{CH}_{2}\right), 1.31-1.14\left(\mathrm{~m}, 1600 \mathrm{H}, \mathrm{CH}_{2}\right), 0.77\left(\mathrm{~m}, 600 \mathrm{H},-\mathrm{CH}_{3}\right) ; \mathrm{m} / z$ (MALDI-ToF) $54406\left(\mathrm{C}_{3400} \mathrm{H}_{4100} \mathrm{~N}_{200} \mathrm{O}_{200} \mathrm{Zn}_{50}, \mathrm{M}^{+}\right.$requires 54239). 

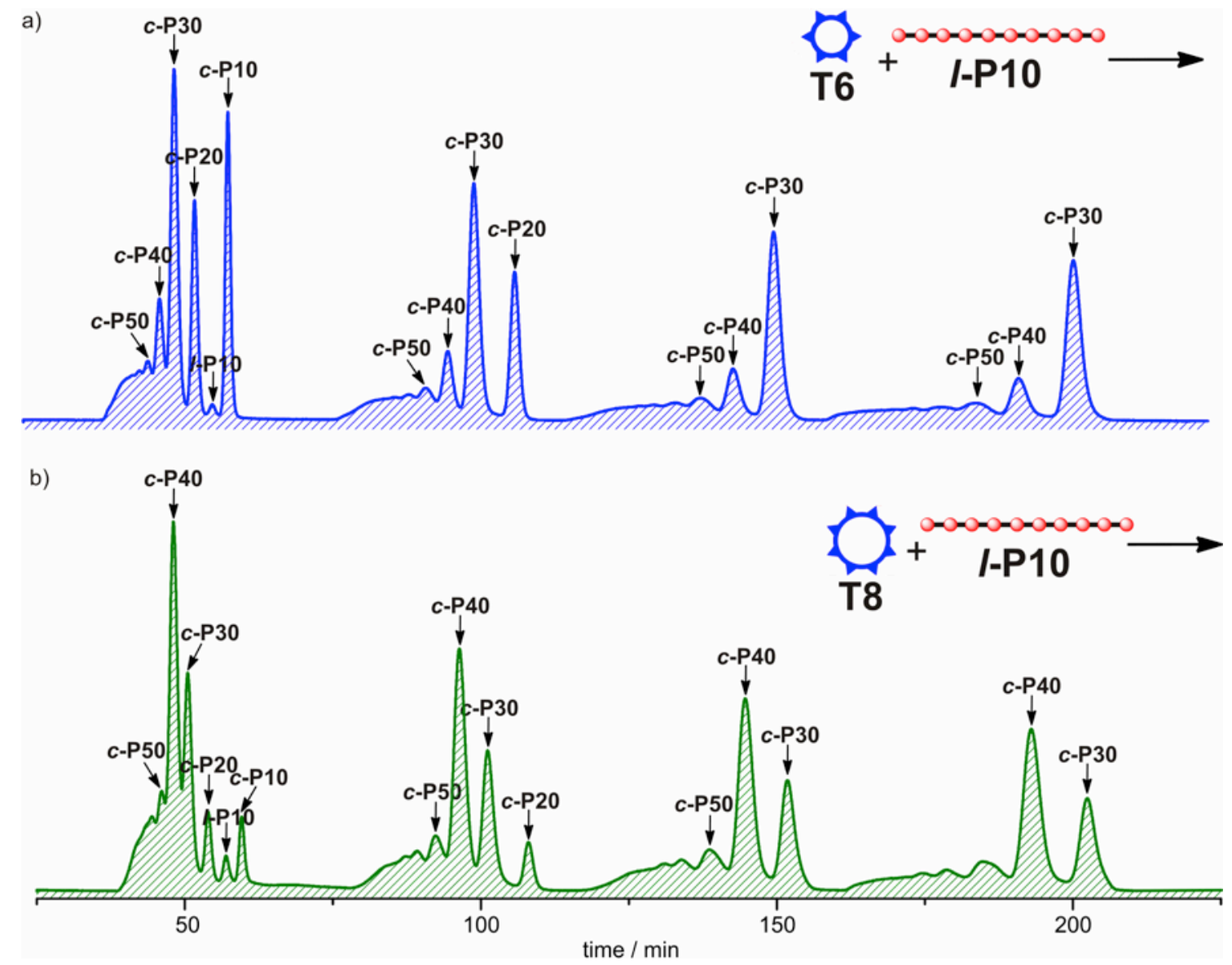

Figure S1. Analytical recycling GPC traces (toluene/1\% pyridine, detection at $500 \mathrm{~nm}$ ) of the crude reaction mixtures of coupling $l$-P10 in the presence of T6 (a) or T8 (b). Each sample was recycled 4 times. Resolved peaks were collected after $1^{\text {st }}\left(\boldsymbol{l}\right.$-P10 and $\boldsymbol{c}$-P10) and $2^{\text {nd }}(\boldsymbol{c}$-P20) cycles to compensate for the broadening of the chromatogram. The catalysts and 1,4-benzoquinone have been removed by passing a sample of the reaction mixture through a short GPC column in $\mathrm{CHCl}_{3} / 10 \%$ pyridine as eluent. Analytical yields were deduced by integration of resolved GPC peak areas, from the absorption at $500 \mathrm{~nm}$, assuming that all species have the same extinction coefficient per porphyrin unit at this wavelength, and that there is no adsorption of material onto the GPC columns.

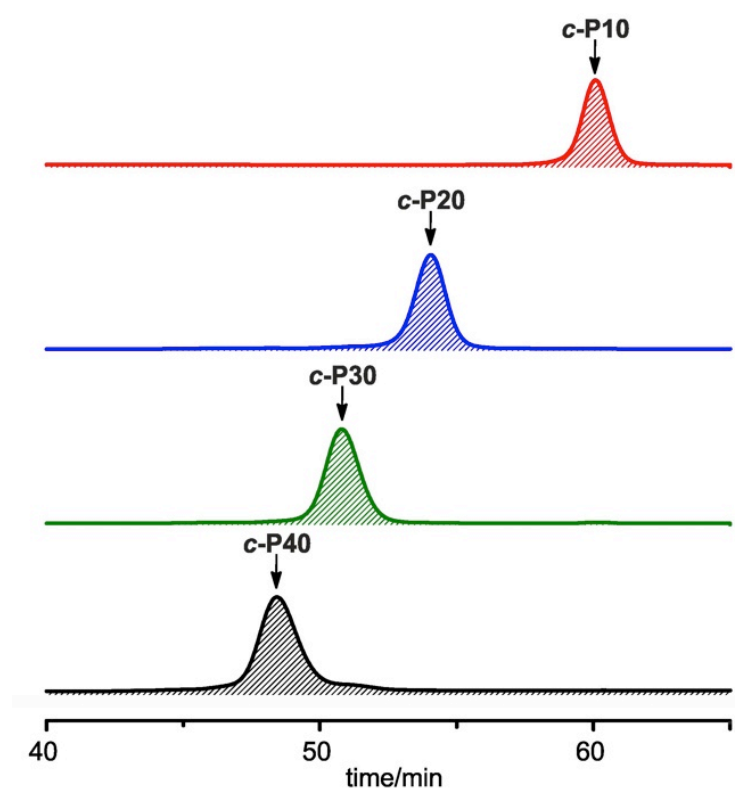

Figure S2. Analytical GPC traces (toluene/1\% pyridine, detection at $500 \mathrm{~nm}$ ) of purified nanorings $\boldsymbol{c}$-P10, $\boldsymbol{c}$-P20, $\boldsymbol{c}$-P30 and $c$-P40. 


\section{Characterisation}

C1. Linear porphyrin 10-mer I-P10

\section{C1a. ${ }^{1}$ H-NMR analysis}

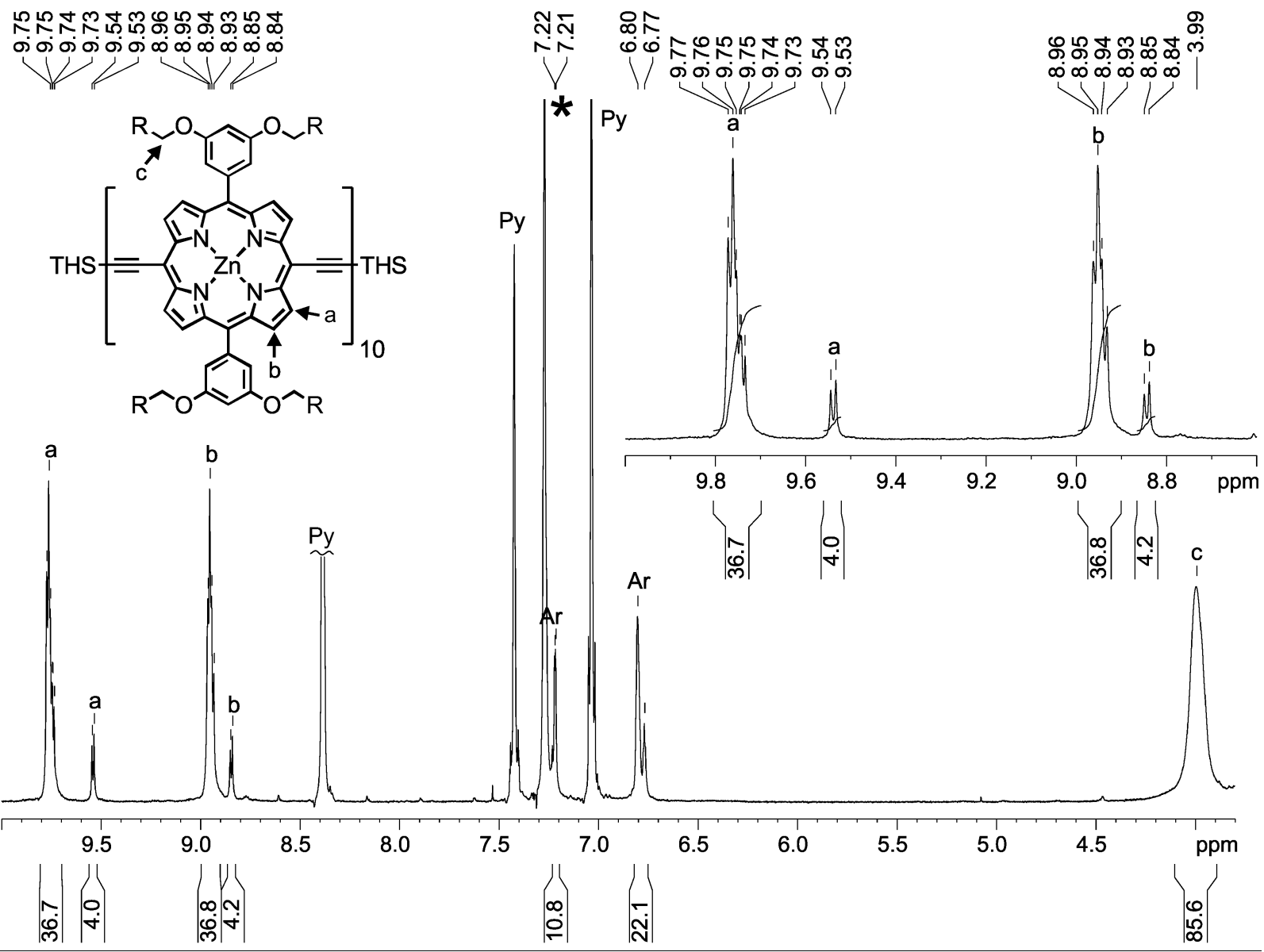

Figure S3. ${ }^{1} \mathrm{H}$ NMR spectrum of $\boldsymbol{l}$-P10 ${ }_{\text {THS,THS }}$ with zoom on the $\beta$-pyrrole region $\left(400 \mathrm{MHz}, \mathrm{CDCl}_{3} / 1 \% d_{5}\right.$-pyridine).

\section{C1b. MALDI-ToF}

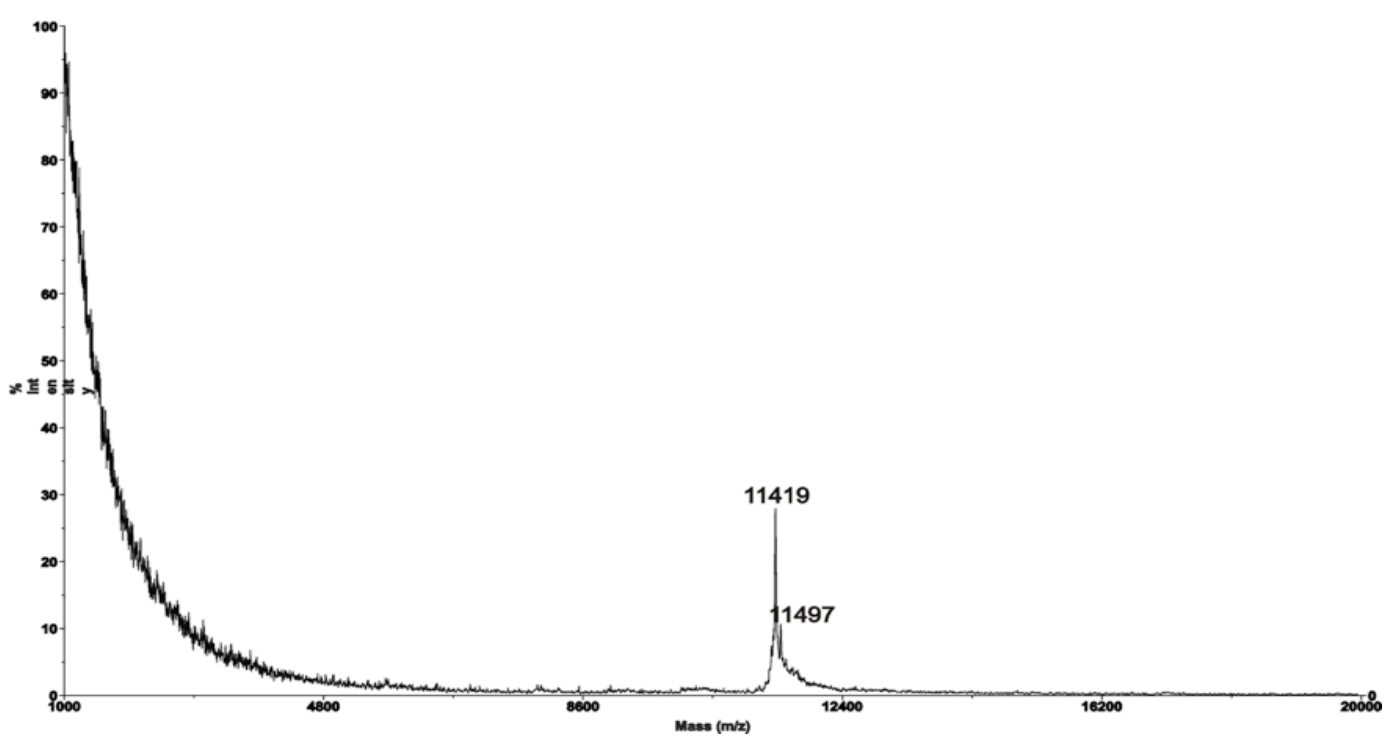

Figure S4. MALDI-ToF analysis of $\boldsymbol{l}$-P10 ${ }_{\text {THS,THS. The major peak corresponds to } \boldsymbol{l} \text {-P10 }}$ THS,THS $(\mathrm{m} / z$ 11419, expected 11415). DCTB was used as matrix. 


\section{C2a. ${ }^{1}$ H-NMR analysis}

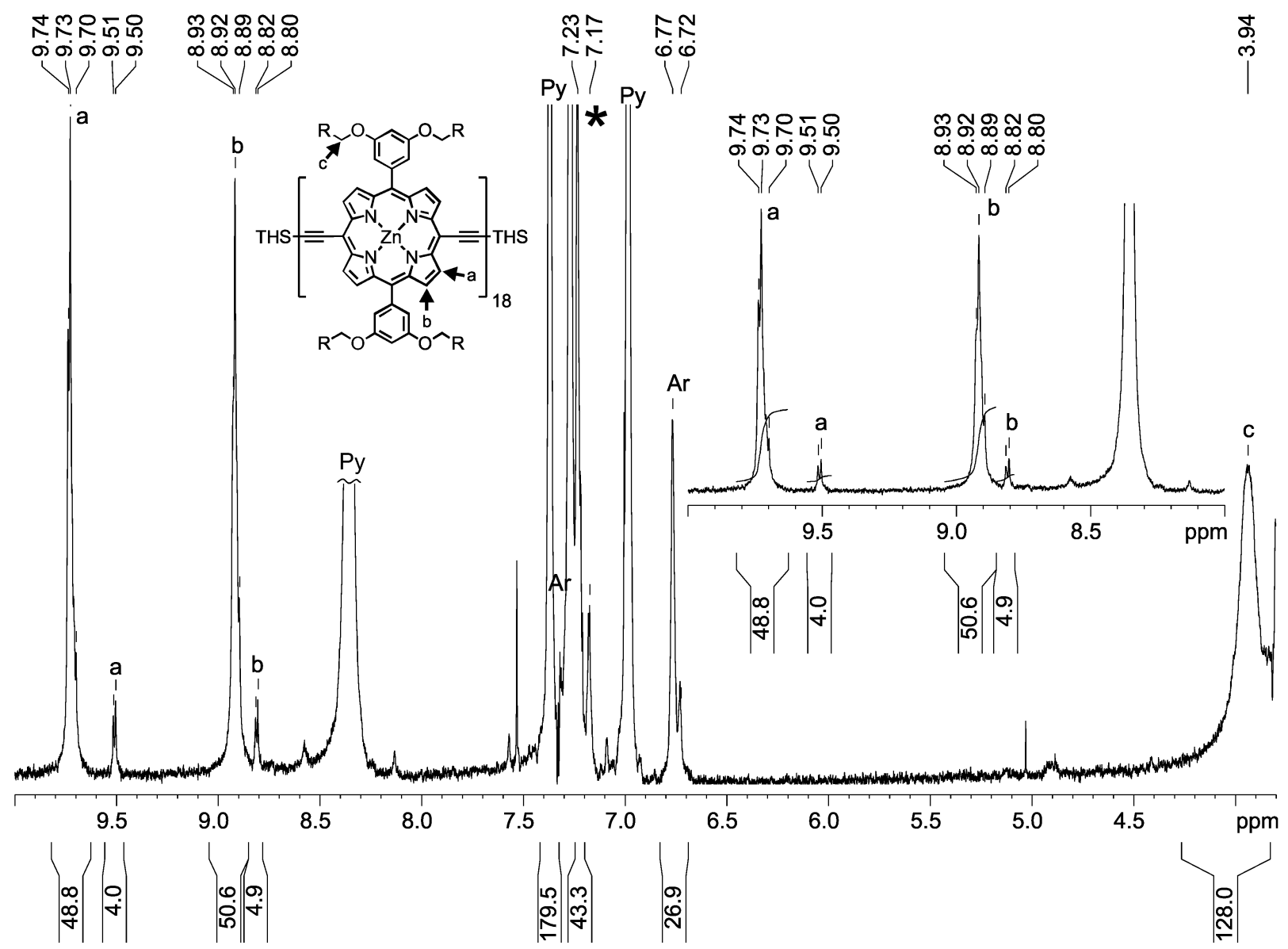

Figure S5. ${ }^{1} \mathrm{H}$ NMR spectrum of $\boldsymbol{l}$-P18 $\mathbf{T H A S}_{\text {THS }}$ with zoom on the $\beta$-pyrrole region $\left(400 \mathrm{MHz}, \mathrm{CDCl}_{3} / 1 \% d_{5}\right.$-pyridine).

\section{C2b. MALDI-ToF}

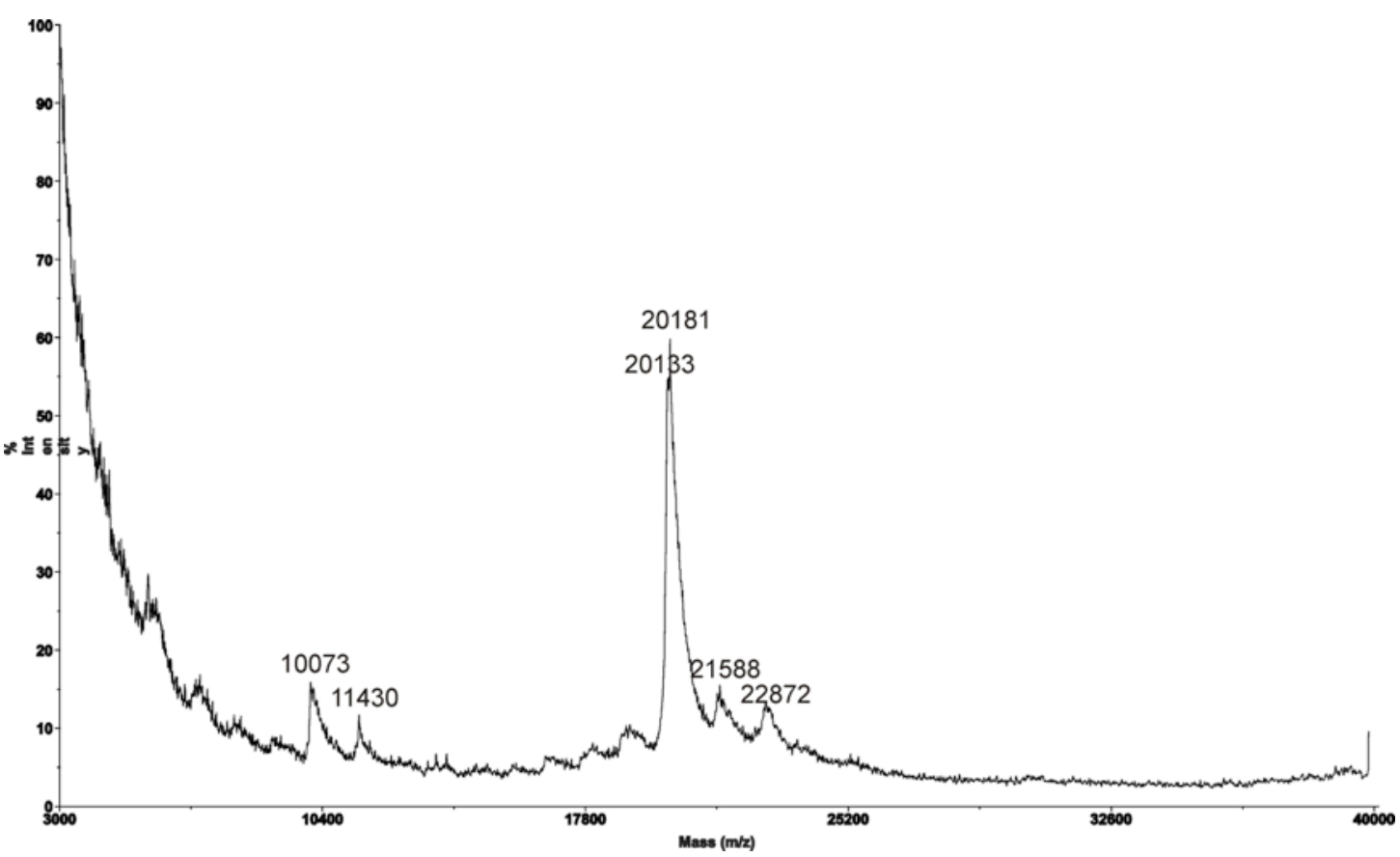

Figure S6. MALDI-ToF analysis of $\boldsymbol{l}$-P18 ${ }_{\text {THS,THS. The major peak corresponds to } \boldsymbol{l} \text {-P18 }}$ THS,THS $(\mathrm{m} / z 20181$ expected 20093). DCTB was used as matrix. 


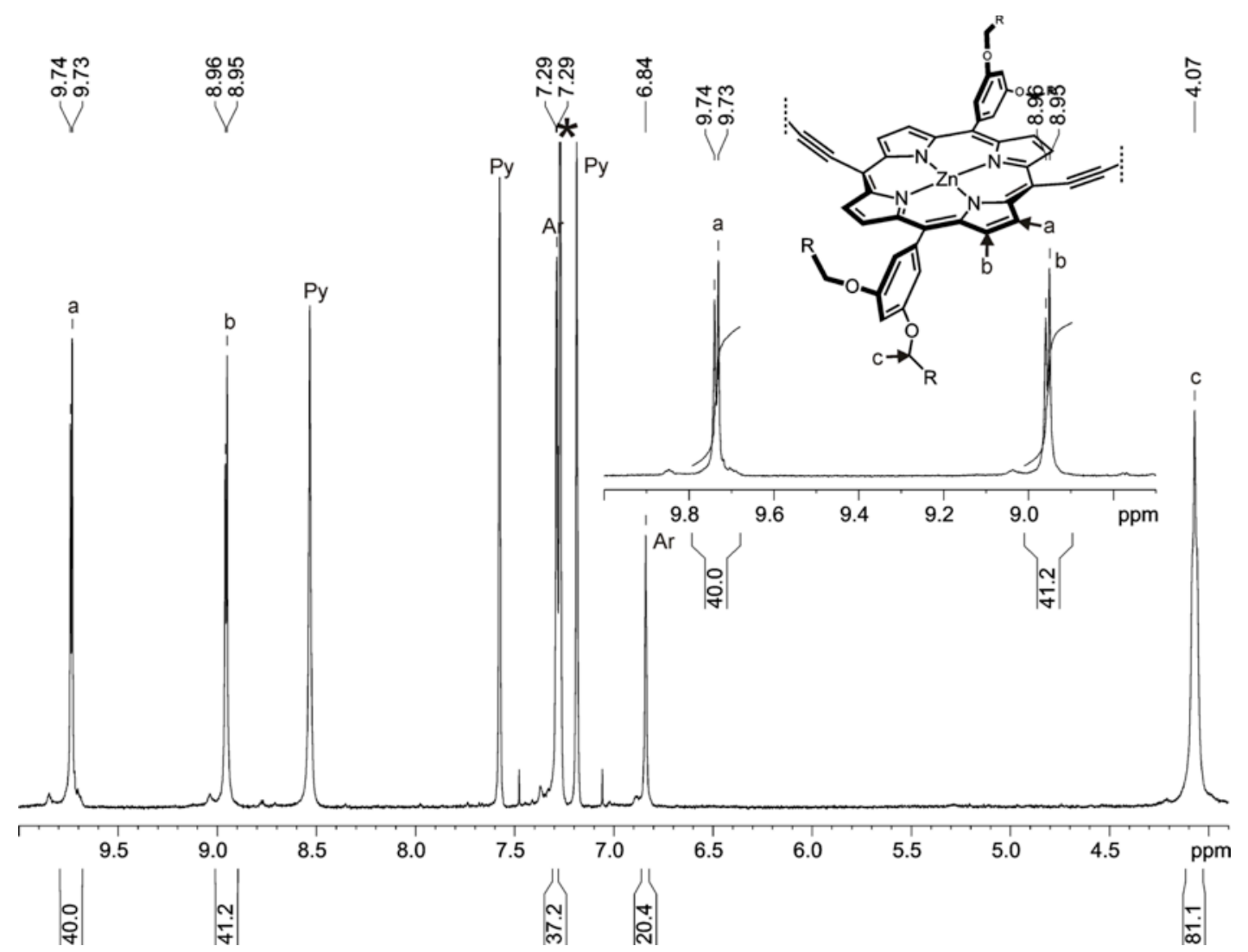

Figure S7. ${ }^{1} \mathrm{H}$ NMR spectrum of $\boldsymbol{c}$-P10 with zoom on the $\beta$-pyrrole region ( $500 \mathrm{MHz}, \mathrm{CDCl}_{3} / 1 \% d_{5}$-pyridine).

\section{C3b. MALDI-ToF}

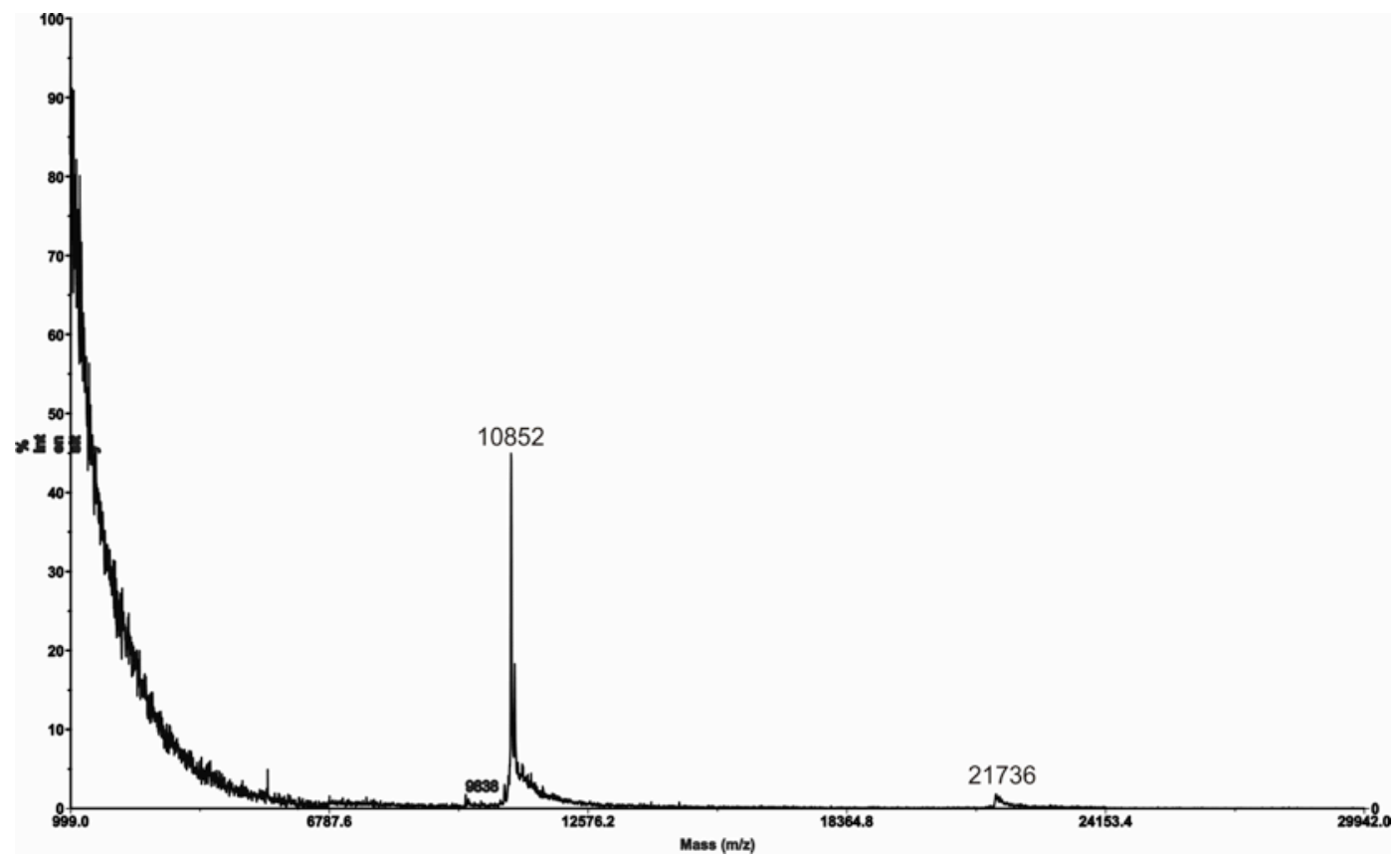

Figure S8. MALDI-ToF analysis of $\boldsymbol{c}$-P10. The major peak corresponds to $\boldsymbol{c}$-P10 $(\mathrm{m} / z$ 10852, expected 10848). DCTB was used as matrix 
C4. Cyclic porphyrin 20-mer c-P20

C4a. ${ }^{1}$ H-NMR analysis

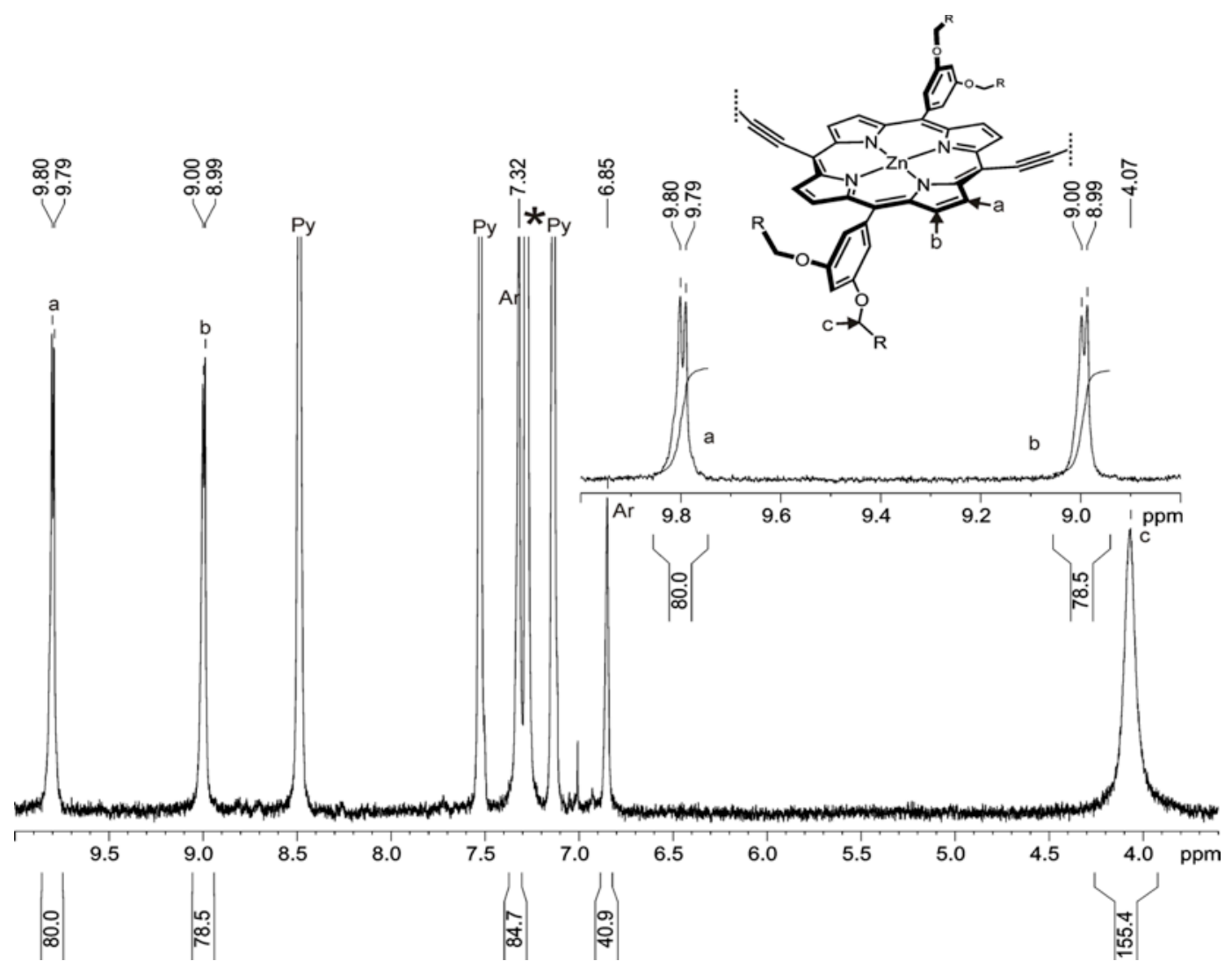

Figure S9. ${ }^{1} \mathrm{H}$ NMR spectrum of $\boldsymbol{c}$-P20 with zoom on the $\beta$-pyrrole region ( $400 \mathrm{MHz}, \mathrm{CDCl}_{3} / 1 \% d_{5}$-pyridine).

\section{C4b. MALDI-ToF}

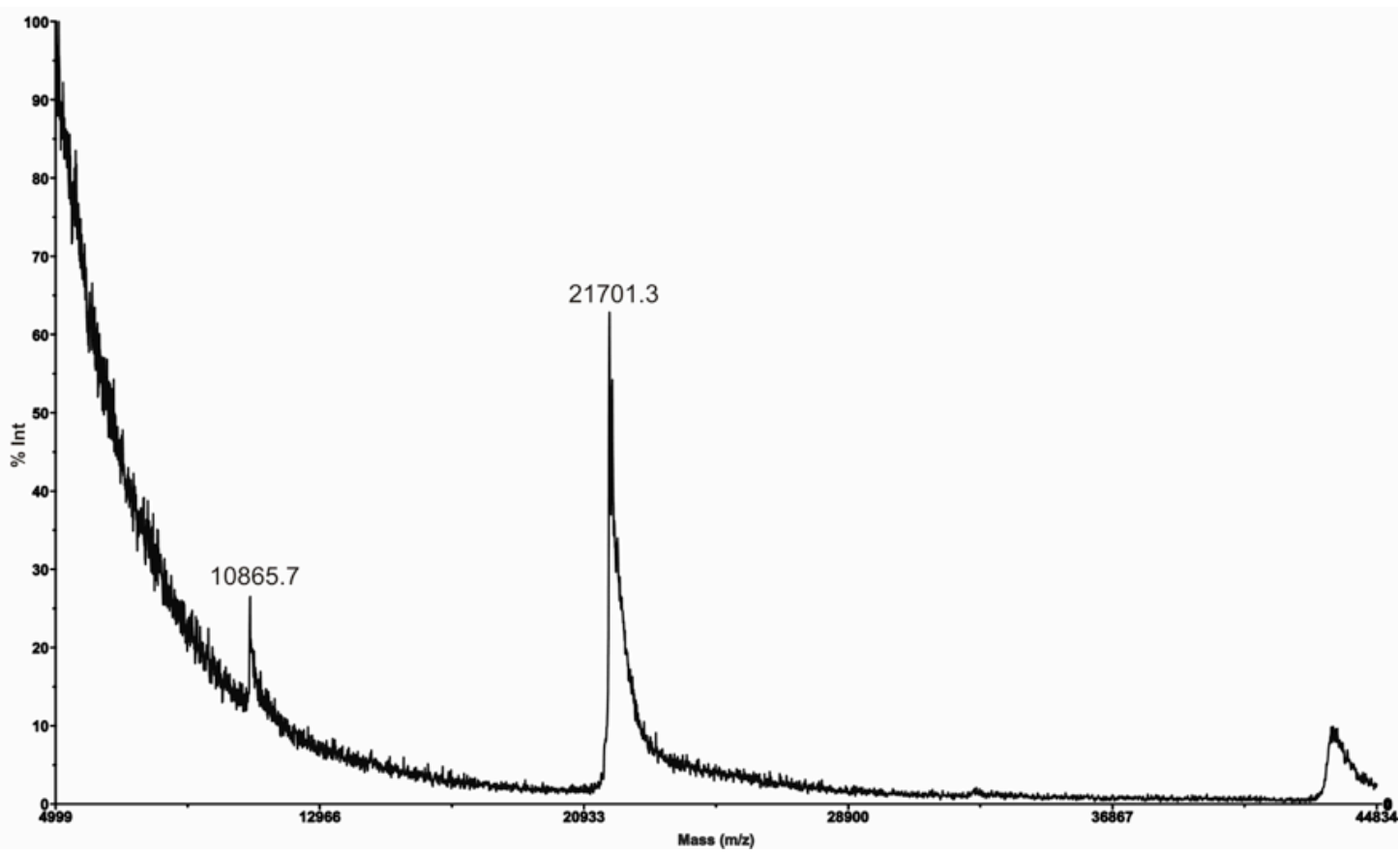

Figure S10. MALDI-ToF analysis of $\boldsymbol{c}$-P20. The major peak corresponds to $\boldsymbol{c}$-P20 $(\mathrm{m} / \mathrm{z} 21701$, expected 21696). DCTB was used as matrix. 
C5. Cyclic porphyrin 30-mer c-P30

C5a. ${ }^{1}$ H-NMR analysis

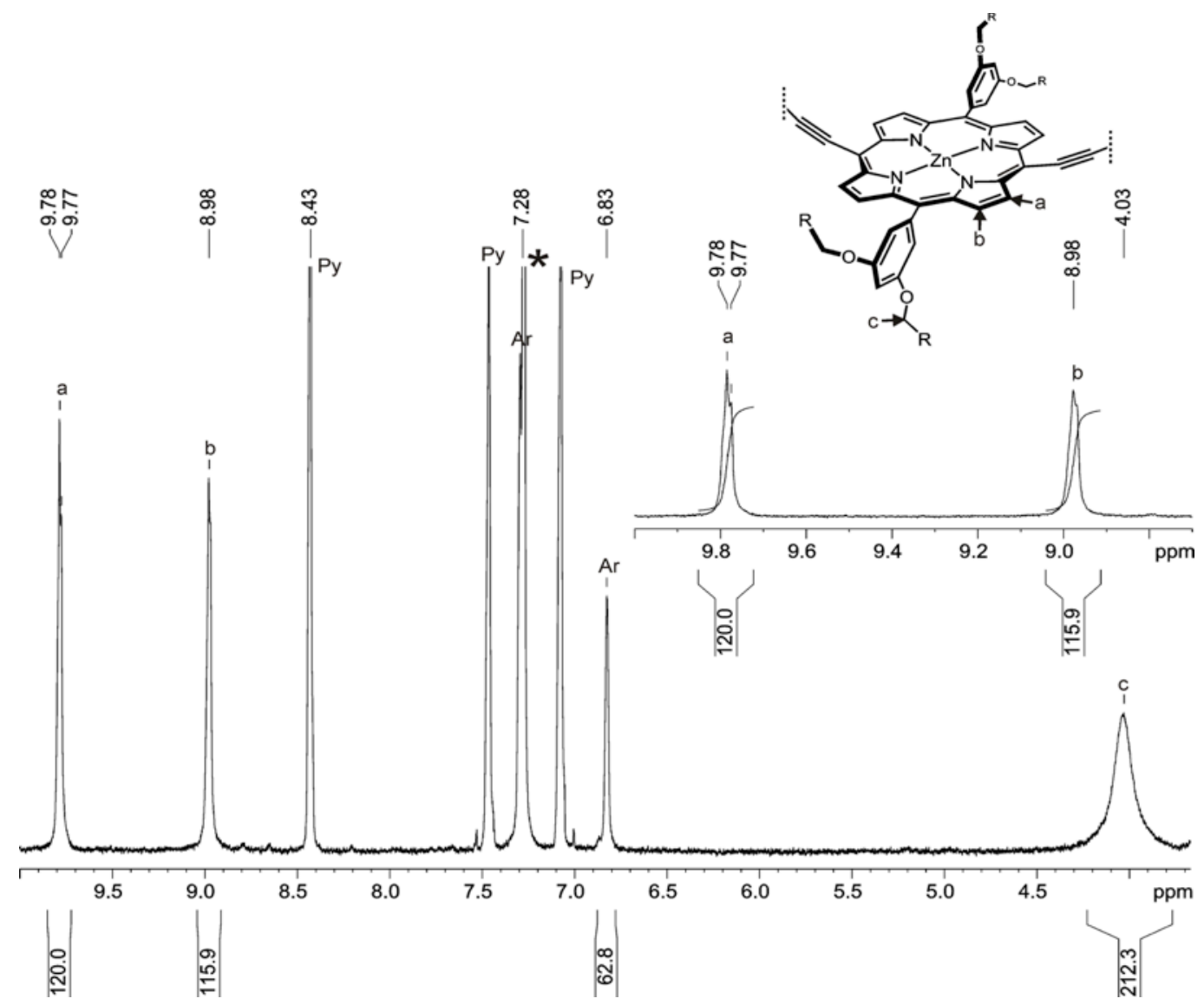

Figure S11. ${ }^{1} \mathrm{H}$ NMR spectrum of $\boldsymbol{c}$-P30 with zoom on the $\beta$-pyrrole region ( $400 \mathrm{MHz}, \mathrm{CDCl}_{3} / 1 \% d_{5}$-pyridine).

\section{C5b. MALDI-ToF}

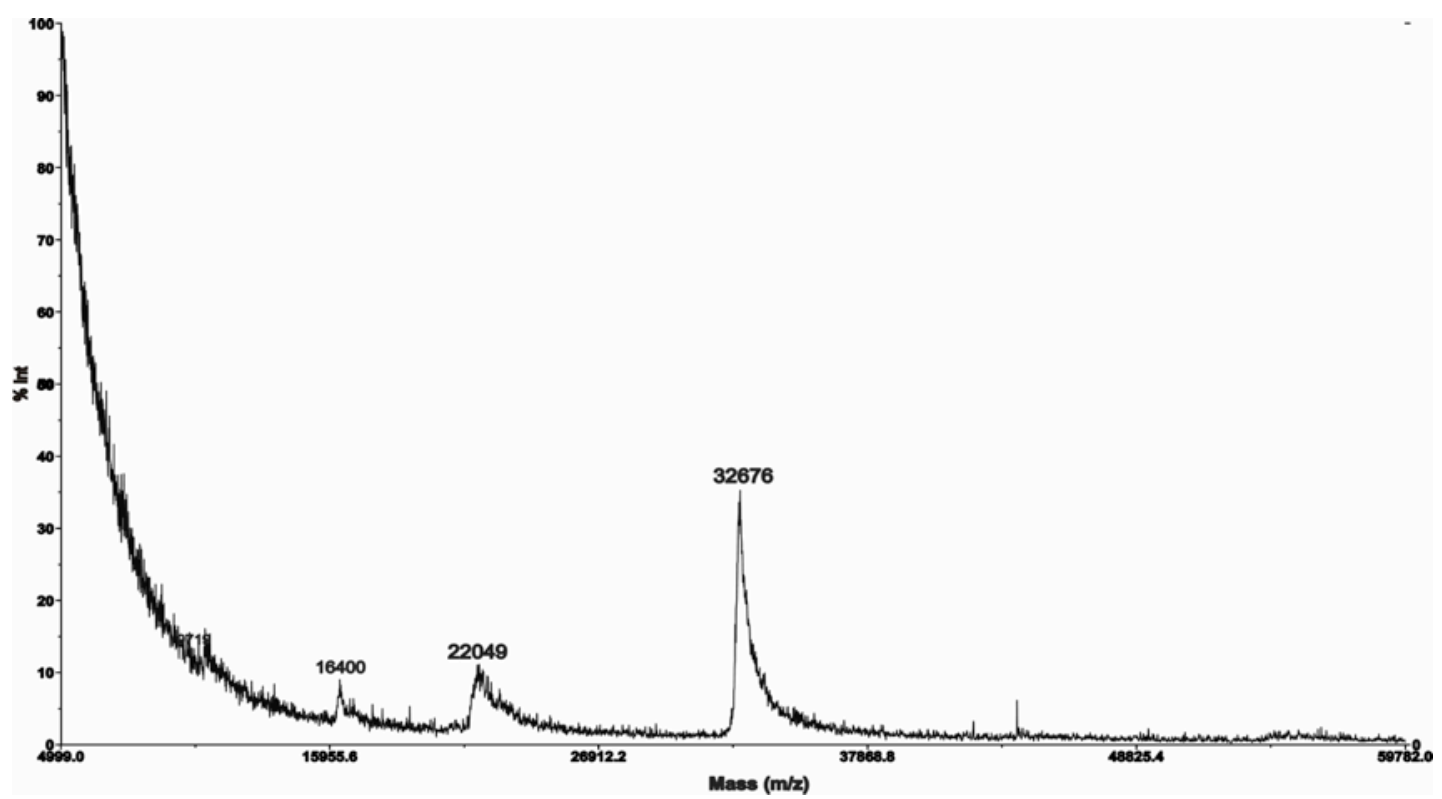

Figure S12. MALDI-ToF analysis of $\boldsymbol{c}$-P30. The major peak corresponds to $\boldsymbol{c}$-P30 $(\mathrm{m} / \mathrm{z} 32676$, expected 32543). DCTB was used as matrix. 
C6. Cyclic porphyrin 40-mer c-P40

C6a. ${ }^{1}$ H-NMR analysis

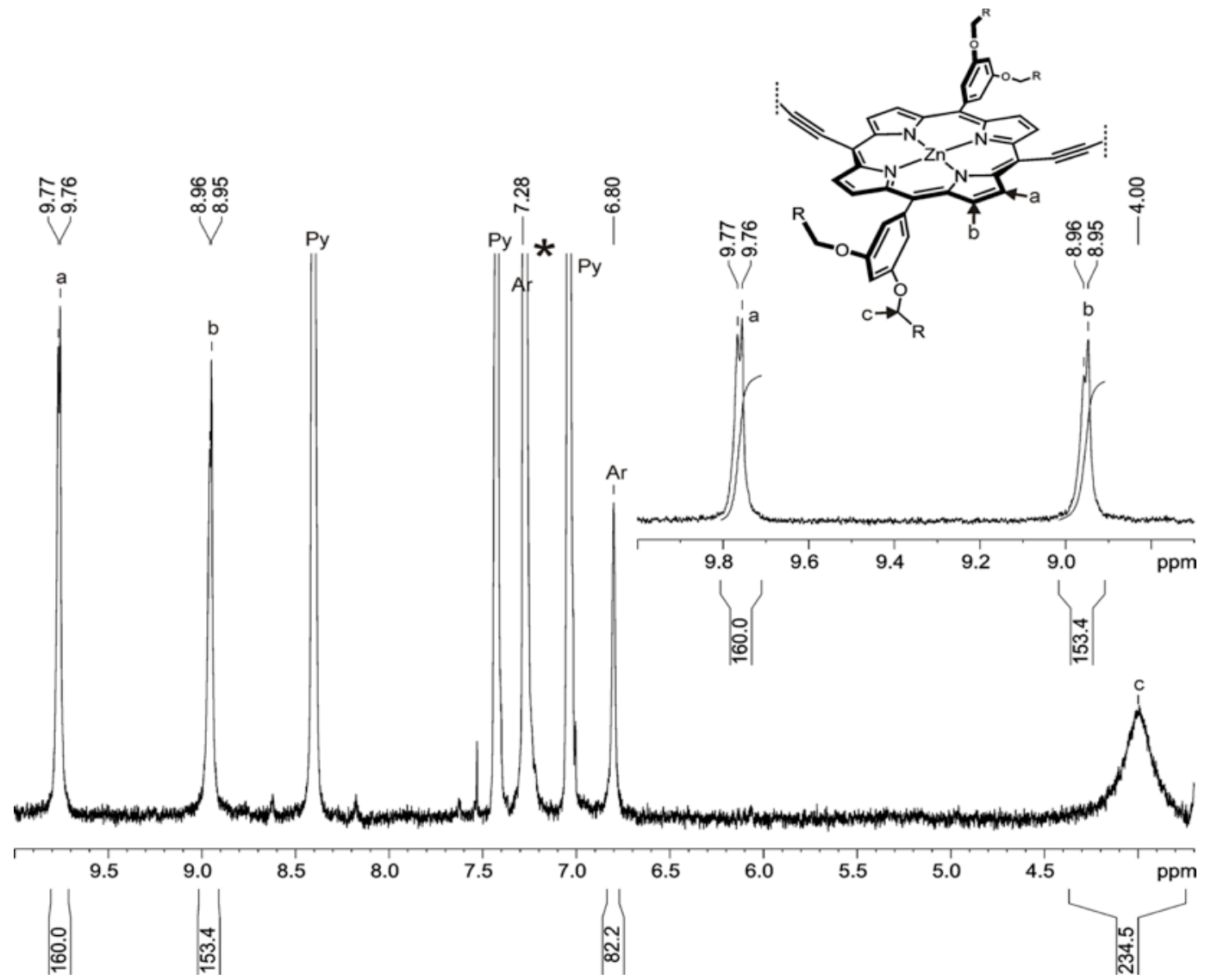

Figure S13. ${ }^{1} \mathrm{H}$ NMR spectrum of $\boldsymbol{c}$-P40 with zoom on the $\beta$-pyrrole region ( $400 \mathrm{MHz}, \mathrm{CDCl}_{3} / 1 \% d_{5}$-pyridine).

\section{C6b. MALDI-ToF}

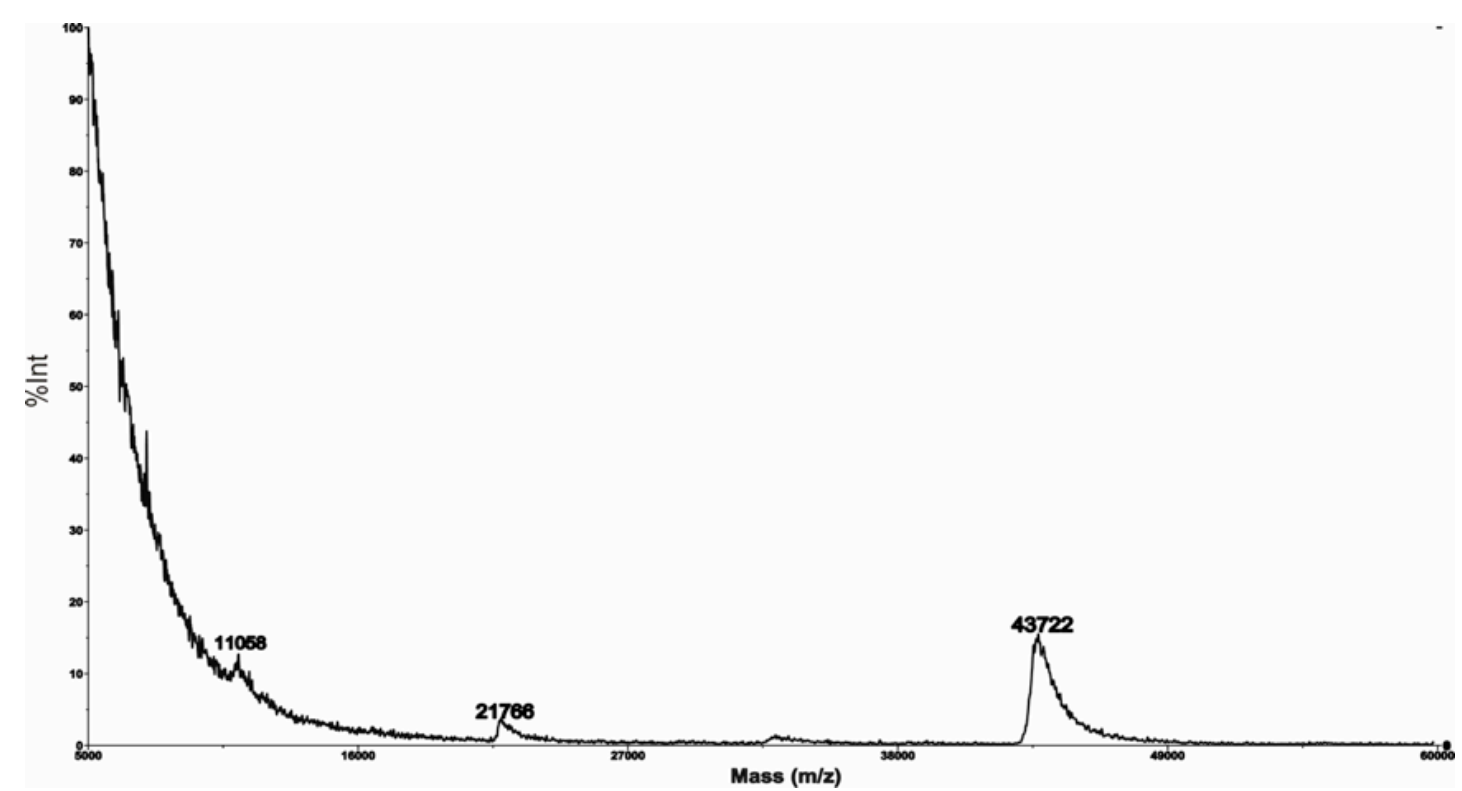

Figure S14. MALDI-ToF analysis of $\boldsymbol{c}$-P40. The major peak corresponds to $\boldsymbol{c}$-P40 $(\mathrm{m} / z$ 43722, expected 43391). DCTB was used as matrix. 


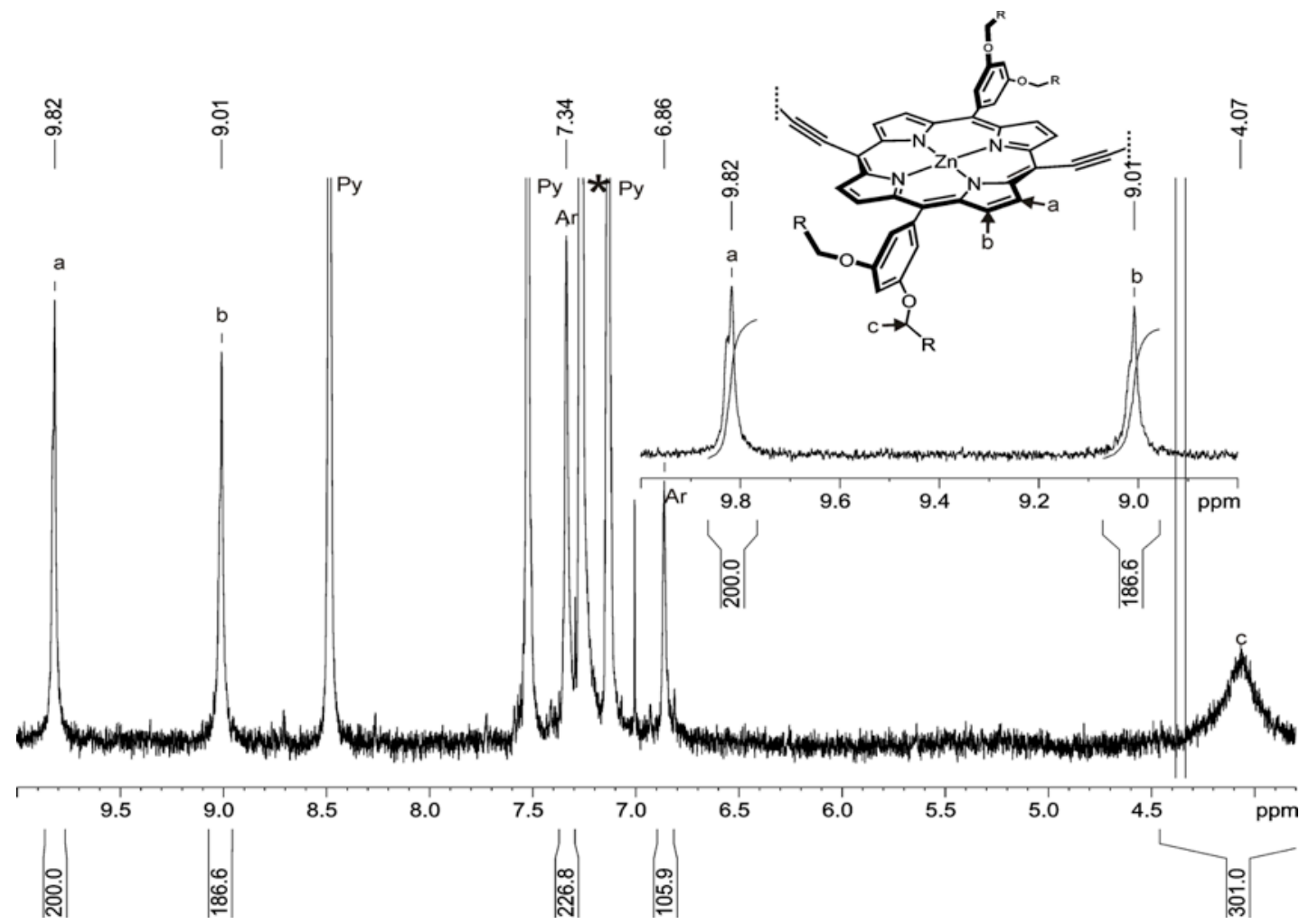

Figure S15. ${ }^{1} \mathrm{H}$ NMR spectrum of $\boldsymbol{c}$-P50 with zoom on the $\beta$-pyrrole region $\left(400 \mathrm{MHz}, \mathrm{CDCl}_{3} / 1 \% d_{5}\right.$-pyridine)

\section{C7b. MALDI-ToF}

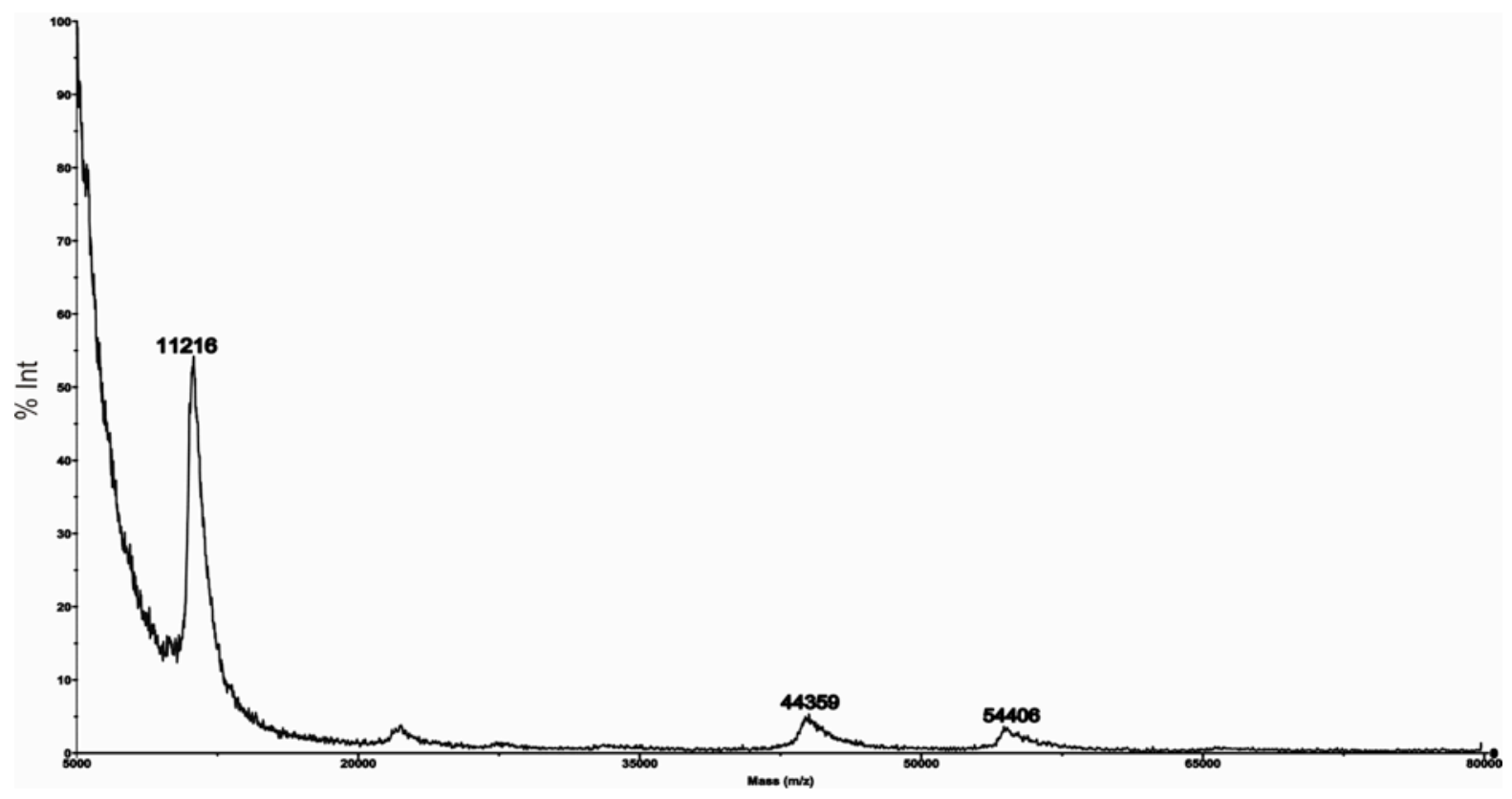

Figure S16. MALDI-ToF analysis of the impure sample of $\boldsymbol{c}$-P50. The major peak correspond to $\boldsymbol{l}$-P10 $(\mathrm{m} / z 11216$, expected 10851), but the spectrum also features peaks of $\boldsymbol{c}$-P50 $(\mathrm{m} / \mathrm{z}$ 54406, expected 54239) and $\boldsymbol{l}$-P40 ( $\mathrm{m} / z 44359$, expected 43393) consistent with STM analysis. DCTB was used as matrix. 


\section{UV/Vis/NIR absorption of $c-\mathrm{P} 10, c-\mathrm{P20}, c-\mathrm{P30}$ and $c-\mathrm{P} 40$}
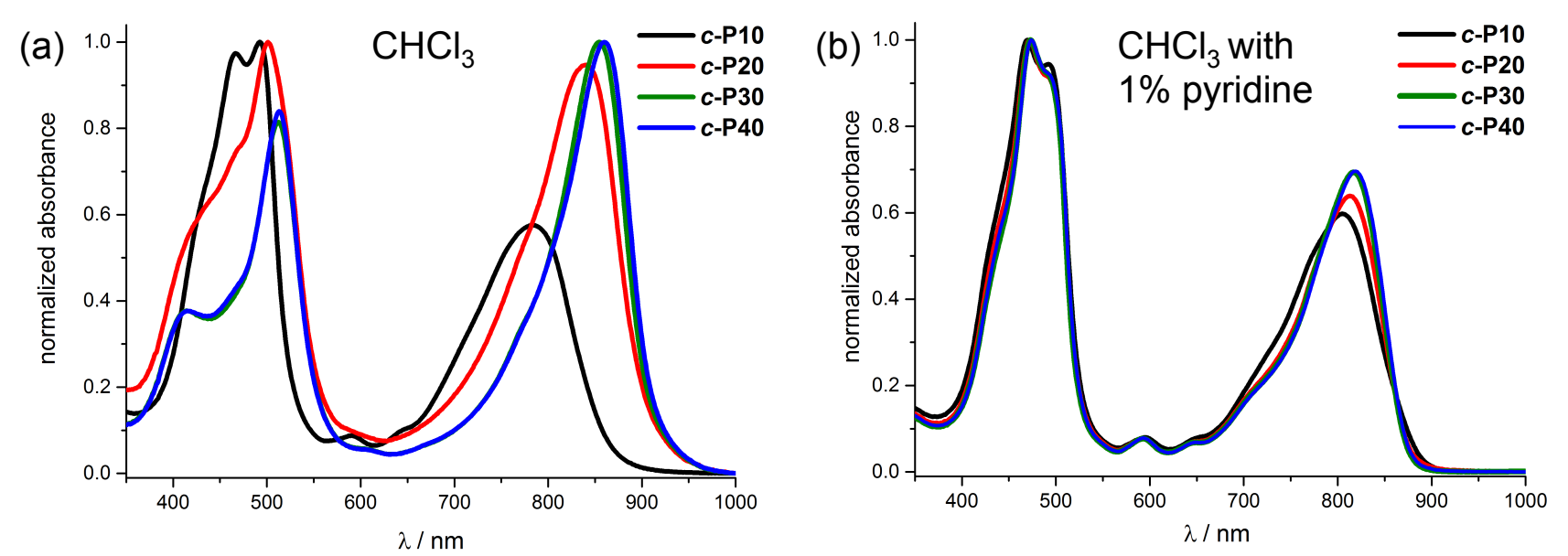

Figure S17. Optical absorption spectra of $\boldsymbol{c}$-P10 (black line), $\boldsymbol{c}$-P20 (red line), $\boldsymbol{c}-\mathbf{P 3 0}$ (orange line) and $\boldsymbol{c}-\mathbf{P 4 0}$ (blue line) measured in (a) $\mathrm{CHCl}_{3}$ and (b) $\mathrm{CHCl}_{3} / 1 \%$ pyridine

\section{E. Scanning tunnelling microscopy}

\section{E1. Preparation and imaging of gold surfaces}

A gold on mica substrate $(4 \mathrm{~mm} \times 8 \mathrm{~mm}$, thickness $300 \mathrm{~nm}$; supplied commercially by Georg Albert PVD) was loaded into a UHV system with a base pressure of $3 \times 10^{-10}$ Torr. The sample was cleaned by Ar ion sputtering $\left(6 \times 10^{-6}\right.$ Torr, $\left.0.8 \mathrm{KeV}, \sim 2 \mu \mathrm{A}\right)$ and subsequent annealing $\left(400{ }^{\circ} \mathrm{C}\right)$. STM images were acquired using electrochemically etched tungsten tips, while operating in constant current mode at room temperature (typically sample bias $-2<V_{s}<-1.8 \mathrm{~V}$, and set-point current $I_{s}=30 \mathrm{pA}$ ). Images of the surface obtained after the sputter-anneal cycle show the characteristic $(22 \times \sqrt{3})$ herringbone reconstruction of the $\mathrm{Au}(111)$ surface. For ambient experiments, gold on mica pieces $(1 \mathrm{~cm} \times 1 \mathrm{~cm})$ were annealed in a butane flame. Before immersion in a solution of nanorings the substrate was allowed to cool to room temperature and STM images were acquired to characterise the quality of the surface termination. Nanorings were deposited by immersion and the susbstrates were then dried in a nitrogen stream. An STM operating under ambient conditions employing tips cut from $\mathrm{Pt} / \mathrm{Ir}$ wire was used to acquire images. All images were processed using WSxM software. ${ }^{\mathrm{S} 7}$

\section{E2. Electrospray deposition}

l-P4 (see below), $\boldsymbol{c}$-P10, $\boldsymbol{c}$-P20, $\boldsymbol{c}$-P30, $\boldsymbol{c}$-P40 and $\boldsymbol{c}$-P50 were dissolved in 75\% toluene, 25\% methanol (by volume) to give a concentration of $\sim 100 \mu \mathrm{g} / \mathrm{mL}$. During UHV-ESD a bias of $\sim 2 \mathrm{kV}$ was applied to the emitter to produce the electrospray event, with the pressure rise in the preparation chamber due to the introduction of the molecular beam measured to be of the order $5 \times$ $10^{-6}$ mbar.

\section{E3. Image of linear oligomer $l$-P4}

The STM image in Fig. S18 shows the linear oligomer $\boldsymbol{l}$-P4 adsorbed on Au(111) following deposition by electrospray. Images are acquired prior to annealing. The spacing of porphyrins in neighbouring oligomers, $\Delta=2.0 \pm 0.15 \mathrm{~nm}$, close to the value of the single-height nanorings discussed in the main text. 


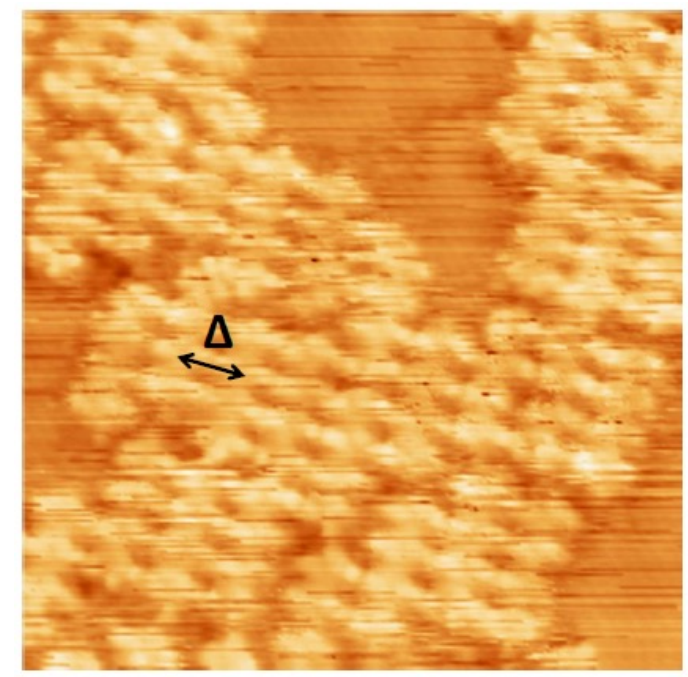

Figure S18. STM Image of the linear porphyrin tetramer $\boldsymbol{l}$-P4 deposited on $\mathrm{Au}(111)$. The spacing between porphyrin, $\Delta$ $=2.0 \pm 0.15 \mathrm{~nm}$.

\section{E4. Additional images of $c-\mathrm{P} 10, c-\mathrm{P20}, c-\mathrm{P30}$ and $c$-P40 acquired in UHV experiments}

Large area STM images show the presence of many nanometer-sized rings (Fig. S18-21). The small area images allow visualising individual porphyrin units and determining the number of porphyrin units in each chain. As expected, $\boldsymbol{c}-\mathbf{P 1 0}, \boldsymbol{c}-\mathbf{P 2 0}, \boldsymbol{c}-\mathbf{P 3 0}$ and $\boldsymbol{c}-\mathbf{P 4 0}$ are the main components present in the samples indicating their high purity.
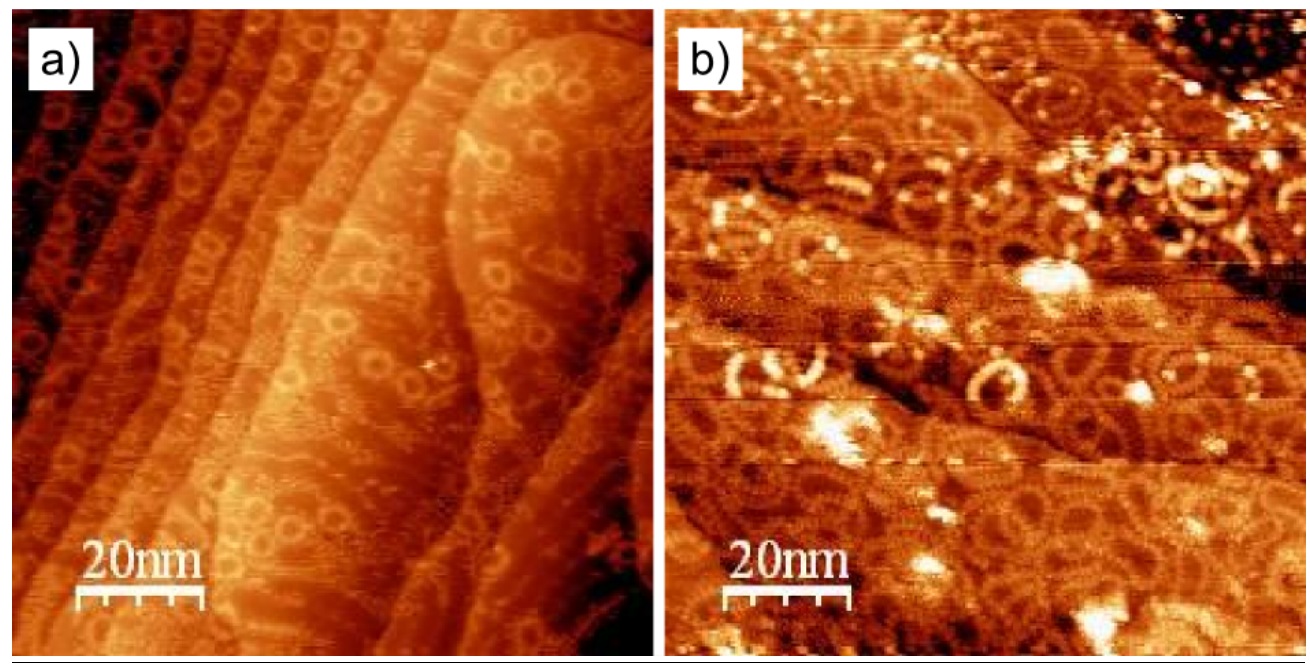

Figure S19. Large area STM images of (a) $c$-P10, (b) $c$-P20. 

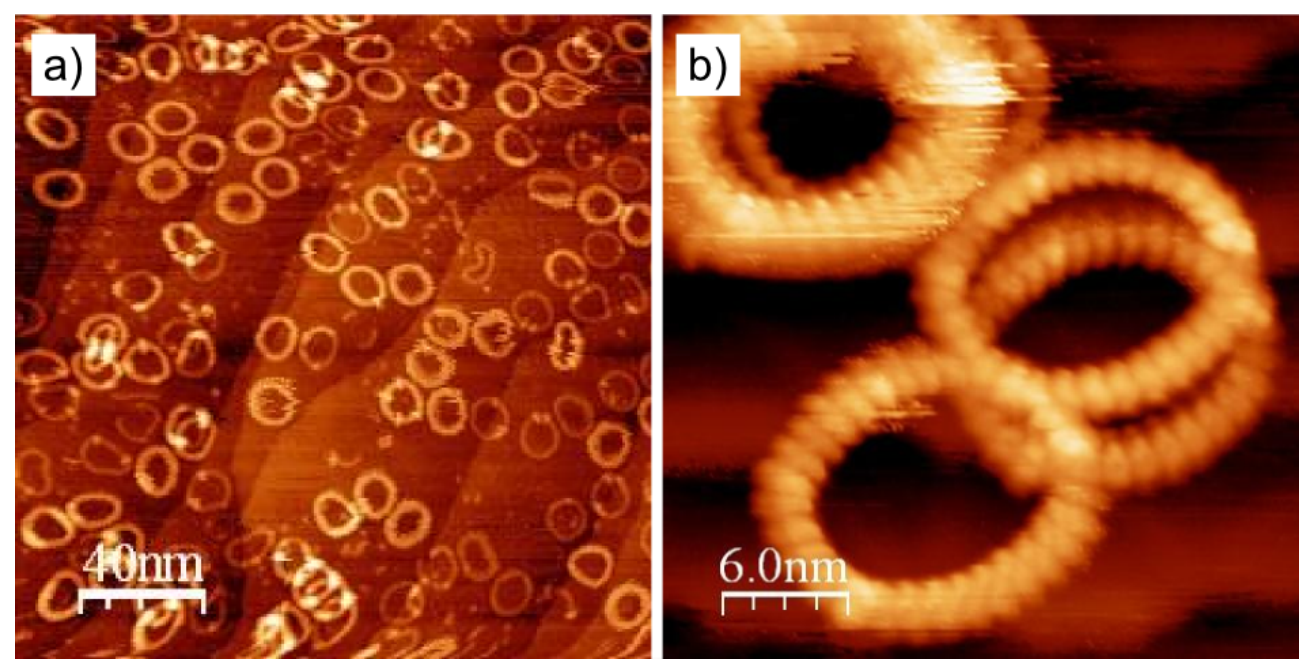

Figure S20. STM images of $\boldsymbol{c}$-P30.
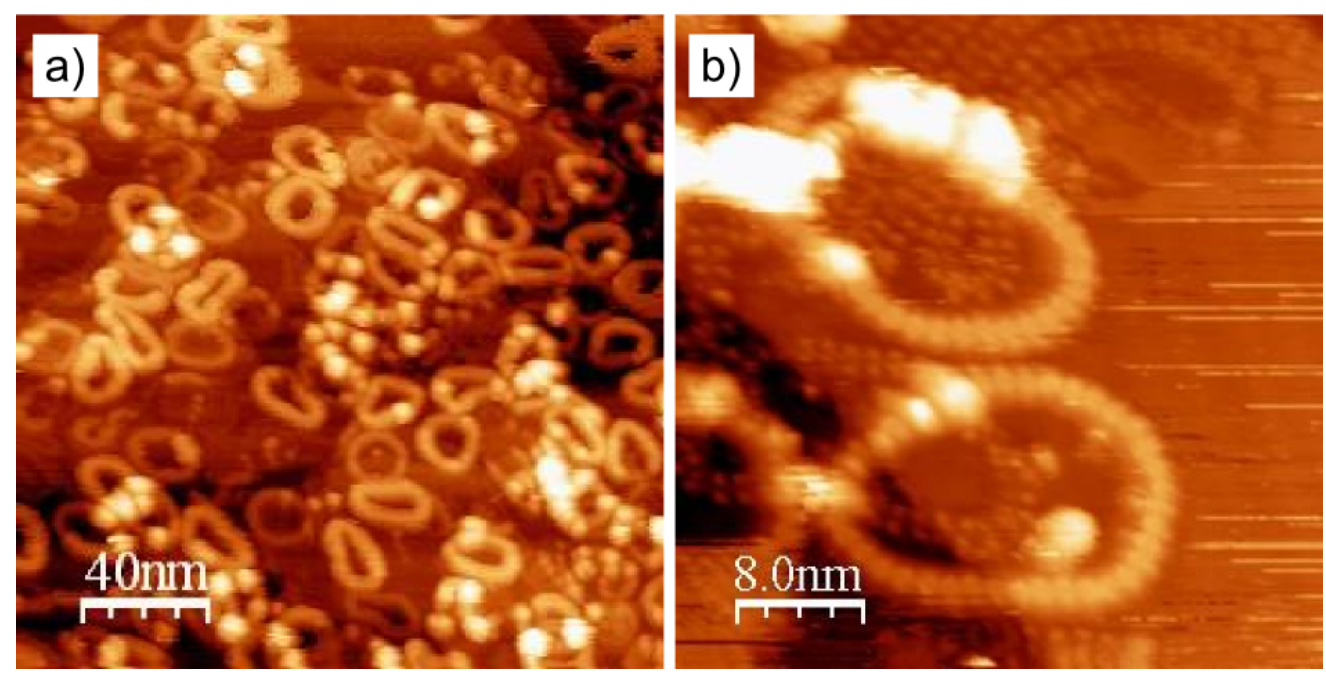

Figure S21. Large (a) and small (b) area STM image of $\boldsymbol{c}$-P40.

\section{E5. Additional images of $c$-P50}

The sample of $\boldsymbol{c}$-P50 used in the experiment was synthesised as described in Section B3e. The recycling GPC analysis as well as MALDI-ToF analysis (Fig. S17) showed that the sample of c-P50 contains traces of other porphyrin oligomers, however due to the small amount of the isolated material $(0.6 \mathrm{mg})$ it was decided to acquire images (Fig. S22) of the material without further purification.

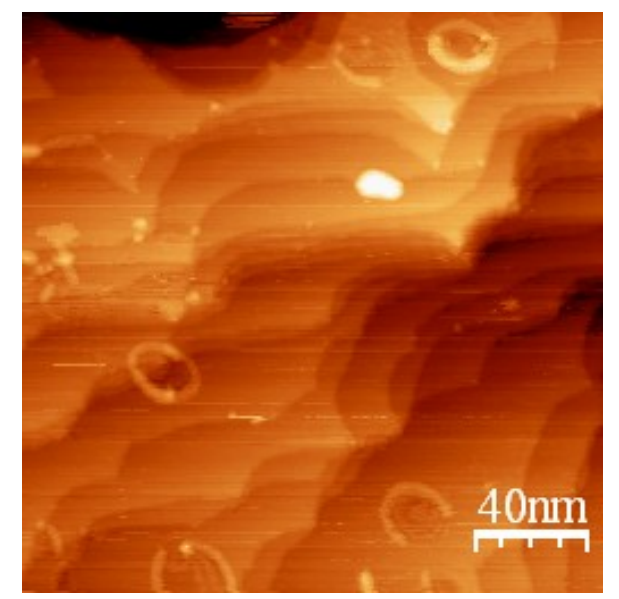

Figure S22. Large area STM image of $\boldsymbol{c}$-P50. 


\section{E6. Height profiles of nested and stacked nanorings}

We show below the height profiles extracted from the images in the main text. The typical topographic heights of single, double and triple stacked nanorings are $\sim 0.15,0.4$ and $0.75 \mathrm{~nm}$ respectively.
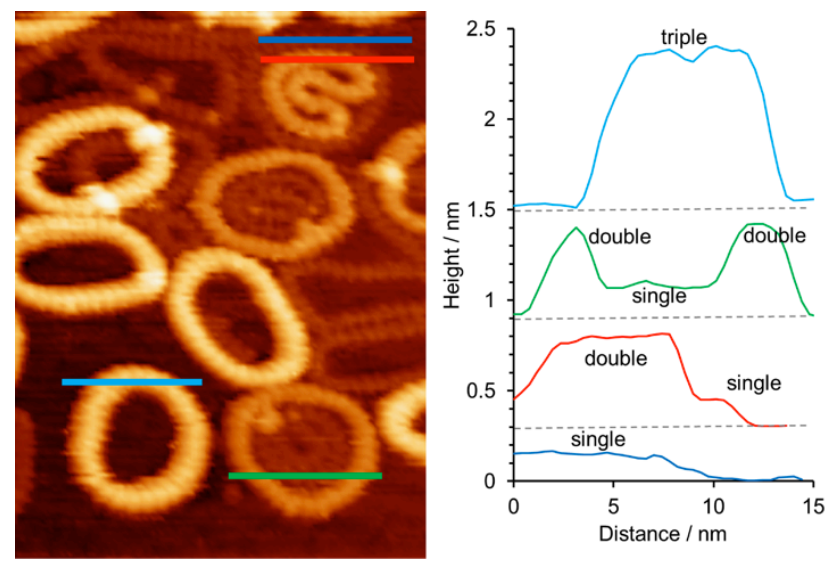

Figure S23. Profiles showing the heights of different stacked and nested $\boldsymbol{c}$-P30. Colour coding provides the correspondence between profile and position on the image. The green and red profiles show the internal and encapsulating rings in single-in-double and double-in-single nested structures respectively.
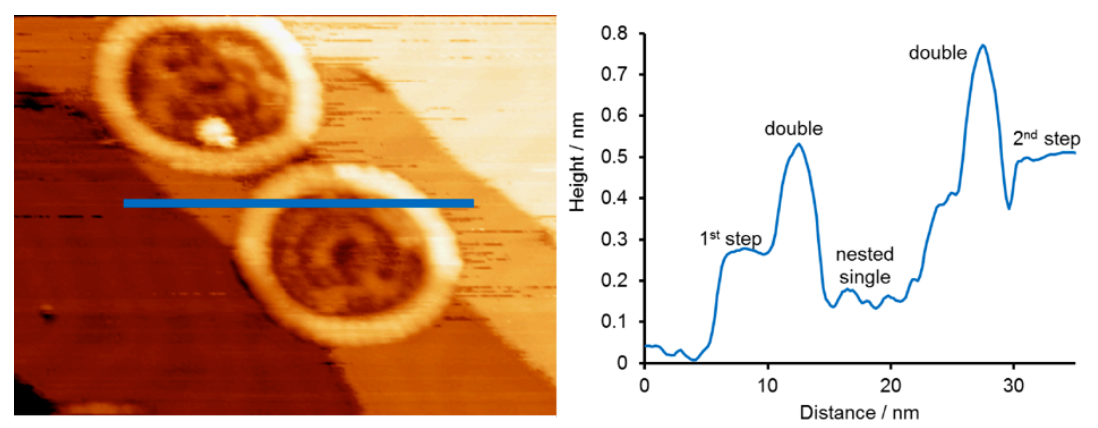

Figure S24. Profiles showing the heights of nested $\boldsymbol{c}$-P40. In this particular image the nested arrangement crosses a terrace step in the underlying gold surface. The difference in height between the 'double' and 'single' on the same terrace is close to the expected value of $0.34 \mathrm{~nm}$.
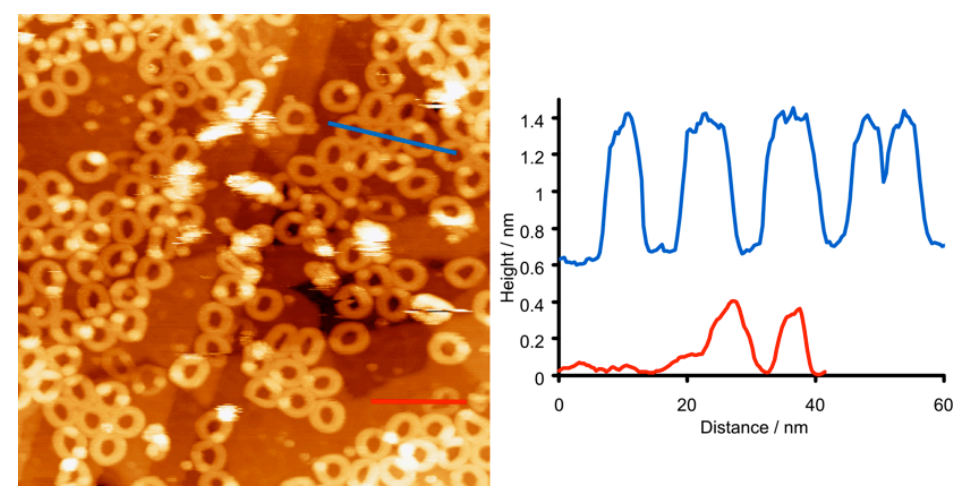

Figure S25. Profiles showing the heights of stacked $\boldsymbol{c}$-P30 deposited from toluene/methanol. The majority of structures correspond to triple stacks with a small number of double stacks (eg red profile). 

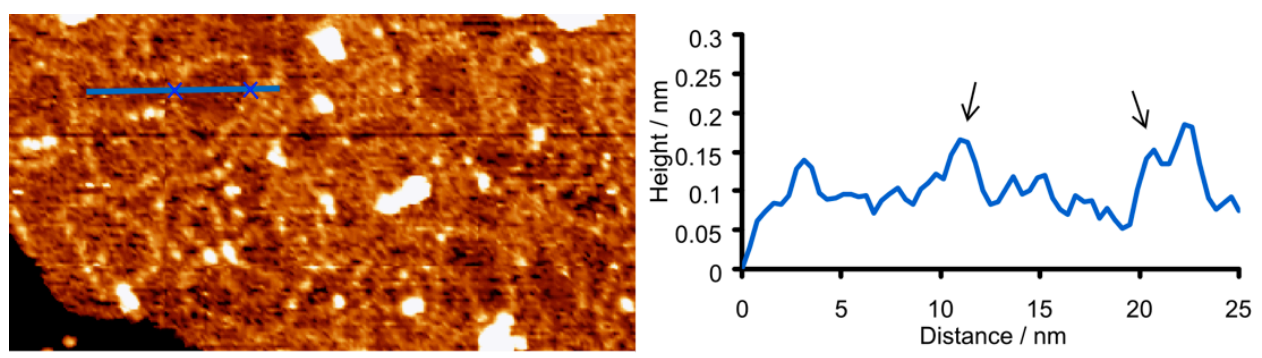

Figure S26. Profiles showing the heights of $\boldsymbol{c}$-P30 deposited from toluene. A uniform contrast is observed corresponding to single height nanorings. The arrows on the profile indicate the points marked by crosses on the image.

\section{F. References}

S1. Chang, M.-H., Hoffmann, M., Anderson, H. L. \& Herz, L. M. Dynamics of excited-state conformational relaxation and electronic delocalization in conjugated porphyrin oligomers, J. Am. Chem. Soc. 125, 1053210533 (2003).

S2. Hoffmann, M., Kärnbratt, J., Chang, M.-H., Herz, L. M., Albinsson, B. \& Anderson H. L. Enhanced $\pi$ conjugation around a porphyrin[6] nanoring, Angew. Chem. Int. Ed. 47, 4993-4996 (2008).

S3. Taylor, P. N. \& Anderson, H. L. Cooperative self-assembly of double-strand conjugated porphyrin ladders, J. Am. Chem. Soc. 121, 11538-115454 (1999).

S4. Hogben, H. J., Sprafke, J. K., Hoffmann, M., Pawlicki, M. \& Anderson, H. L. Stepwise effective molarities in porphyrin oligomer complexes: preorganization results in exceptionally strong chelate cooperativity. J. Am. Chem. Soc 133, 20962-20969 (2011).

S5. Hoffmann, M., Wilson, C. J., Odell, B. \& Anderson H. L. Template-directed synthesis of a $\pi$-conjugated porphyrin nanoring. Angew. Chem. Int. Ed. 46, 3122-3125 (2007).

S6. Williams, V. E. \& Swager, T. M. An improved synthesis of poly(p-phenylenebutadiynylene)s, J. Polym. Sci., Part A: Polym. Chem. 38, 4669-4676 (2000).

S7. Horcas, I., Fernandez, R., Gomez-Rodriguez, J. M., Colchero, J., Gomez-Herrero, J. \& Baro, A. M. WSXM: A software for scanning probe microscopy and a tool for nanotechnology, Rev. Sci. Instrum. 78, 013705 (2007). Available at www.nanotec.es. 